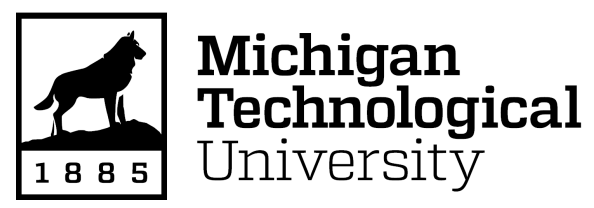

Michigan Technological University Digital Commons @ Michigan Tech

6-7-2016

\title{
Characterization of cumulus cloud fields using trajectories in the center of gravity versus water mass phase space: 2 . Aerosol effects on warm convective clouds
}

\author{
Reuven H. Heiblum \\ Weizmann Institute of Science \\ Orit Altaratz \\ Weizmann Institute of Science \\ Ilan Koren \\ The Weizmann Institute of Science \\ Graham Feingold \\ NOAA Earth System Research Laboratory \\ Alexander Kostinski \\ Michigan Technological University

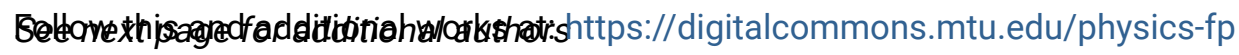 \\ Part of the Physics Commons
}

\begin{abstract}
Recommended Citation
Heiblum, R. H., Altaratz, O., Koren, I., Feingold, G., Kostinski, A., Khain, A., Ovchinnikov, M. S., Dagan, G., Pinto, L., Yaish, R., \& Chen, Q. (2016). Characterization of cumulus cloud fields using trajectories in the center of gravity versus water mass phase space: 2 . Aerosol effects on warm convective clouds. Journal of Geophysical Research: Atmospheres, 121(11), 6356-6373. http://dx.doi.org/10.1002/2015JD024193 Retrieved from: https://digitalcommons.mtu.edu/physics-fp/169
\end{abstract}

Follow this and additional works at: https://digitalcommons.mtu.edu/physics-fp

Part of the Physics Commons 


\section{Authors}

Reuven H. Heiblum, Orit Altaratz, Ilan Koren, Graham Feingold, Alexander Kostinski, Alexander Khain, Mikhail S. Ovchinnikov, Guy Dagan, Lital Pinto, Ricki Yaish, and Qian Chen 


\section{Journal of Geophysical Research: Atmospheres}

\section{RESEARCH ARTICLE}

10.1002/2015JD024193

This article is a companion to Heiblum et al. [2016] doi:10.1002/2015JD024186.

\section{Key Points:}

- Aerosol effects on clouds as reflected in the cloud center of gravity versus mass phase space

- Aerosol concentration correlates with cloud center of gravity during cloud growing stage

- Indications of aerosol induced warm cloud invigoration

Correspondence to:

I. Koren,

Ilan.Koren@weizmann.ac.il

Citation:

Heiblum, R. H., et al. (2016),

Characterization of cumulus cloud fields using trajectories in the center of gravity versus water mass phase space: 2 . Aerosol effects on warm convective clouds, J. Geophys. Res. Atmos., 121, 6356-6373, doi:10.1002/2015JD024193.

Received 6 SEP 2015

Accepted 16 APR 2016

Accepted article online 20 APR 2016

Published online 7 JUN 2016

\section{Characterization of cumulus cloud fields using trajectories in the center of gravity versus water mass phase space: 2. Aerosol effects on warm convective clouds}

\author{
Reuven H. Heiblum ${ }^{1}$, Orit Altaratz ${ }^{1}$, Ilan Koren ${ }^{1}$, Graham Feingold ${ }^{2}$, Alexander B. Kostinski ${ }^{3}$, \\ Alexander P. Khain ${ }^{4}$, Mikhail Ovchinnikov ${ }^{5}$, Erick Fredj ${ }^{1}$, Guy Dagan ${ }^{1}$, Lital Pinto ${ }^{1}$, Ricki Yaish ${ }^{1}$, \\ and Qian Chen ${ }^{1}$
}

\begin{abstract}
${ }^{1}$ Department of Earth and Planetary Sciences, Weizmann Institute of Science, Rehovot, Israel, ${ }^{2}$ Chemical Sciences Division, NOAA Earth System Research Laboratory (ESRL), Boulder, Colorado, USA, ${ }^{3}$ Department of Physics, Michigan Technological University, Houghton, Michigan, USA, ${ }^{4}$ Institute of Earth Sciences, Hebrew University of Jerusalem, Jerusalem, Israel, ${ }^{5}$ Atmosphere Science and Global Change Division, Pacific Northwest National Laboratory, Richland, Washington, USA
\end{abstract}

Abstract In Part I of this work a 3-D cloud tracking algorithm and phase space of center of gravity altitude versus cloud liquid water mass (CvM space) were introduced and described in detail. We showed how new physical insight can be gained by following cloud trajectories in the CvM space. Here this approach is used to investigate aerosol effects on cloud fields of warm cumuli. We show a clear effect of the aerosol loading on the shape and size of CvM clusters. We also find fundamental differences in the CvM space between simulations using bin versus bulk microphysical schemes, with the bin scheme precipitation expressing much higher sensitivity to changes in aerosol concentrations. Using the bin microphysical scheme, we find that the increase in cloud center of gravity altitude with increase in aerosol concentrations occurs for a wide range of cloud sizes. This is attributed to reduced sedimentation, increased buoyancy and vertical velocities, and increased environmental instability, all of which are tightly coupled to inhibition of precipitation processes and subsequent feedbacks of clouds on their environment. Many of the physical processes shown here are consistent with processes typically associated with cloud invigoration.

\section{Introduction}

The assessment of aerosol effects on clouds and precipitation is considered as one of the biggest challenges in the fields of cloud physics and climate research [Intergovernmental Panel on Climate Change, 2013]. A warm cloud developing in a high aerosol-loading environment would have more but smaller droplets [Squires, 1958; Twomey, 1977] which reduces the efficiency of the collision-coalescence process [Squires, 1958; Warner, 1968; Twomey, 1977], prolongs the diffusional growth time [Khain et al., 2005; Wang, 2005], and delays precipitation [Albrecht, 1989; Rosenfeld et al., 2008]. Moreover, in-cloud condensational growth is more efficient because of the larger surface area-to-volume ratios of droplets [Mordy, 1959; Khain et al., 2005; Reutter et al., 2009; Pinsky et al., 2012; Seiki and Nakajima, 2013; Dagan et al., 2015a, 2015b]. These processes enable the cloud to condense more water, intensify its growth via increased release of latent heat [Kogan and Martin, 1994; Koren et al., 2014], and eventually reach larger sizes (both vertically and horizontally) [Kaufman et al., 2005; Yuan et al., 2011; Koren et al., 2014]. On the other hand, more numerous and small droplets increase evaporation rates in any subsaturated region of the cloud, which can promote entrainment mixing and suppression of cloud growth [Jiang et al., 2006; Xue and Feingold, 2006]. This may also be accompanied by larger drag forces of clouds with more liquid water mass that also suppresses cloud growth. The competition between those opposing processes determines the total aerosol effect on cloud properties such as cloud fraction, lifetime, albedo, mass, size, and precipitation amount. However, the sign and magnitude of such effects are nontrivial [Jiang and Feingold, 2006; Stevens and Feingold, 2009]. Recent work has shown that on a single warm cloud scale, the competition between opposite processes leads to an optimum value of aerosol concentration regarding various cloud properties like total mass or rain. This optimum is highly dependent on the meteorological conditions in which the cloud forms [Dagan et al., 2015b].

Convective cloud invigoration by aerosol links a change in aerosol loading (and therefore changes in the droplet size distribution) to changes in cloud properties through a series of coupled microphysical and 
dynamical feedbacks. Invigoration was shown first for deep convective clouds with a mixed phase region, both from observations [Andreae et al., 2004; Koren et al., 2005] and numerical models [Khain et al., 2005; Khain, 2009] (see reviews by Tao et al. [2012], Altaratz et al. [2014], and Rosenfeld et al. [2014]). Recently, it was suggested that invigoration applies for warm clouds as well and could be viewed as an extension of the case of aerosol-limited clouds [Koren et al., 2014].

In Part I (hereafter PT1 [Heiblum et al., 2016]) of this work we introduced the center of gravity versus mass (CvM) phase space, where the center of gravity is defined as [Grabowski et al., 2006; Koren et al., 2009]

$$
\mathrm{COG}=\frac{\sum_{i} m_{i} z_{i}}{M}
$$

where $m_{i}$ and $z_{i}$ are the respective mass $(\mathrm{kg})$ and height $(\mathrm{m})$ of voxel $i$ of a cloud and $M$ is the total liquid water mass of the cloud. Spanning the cloud field properties in the CvM phase space was shown to be an efficient and informative approach for understanding many characteristics of a cloud field output from numerical models, such as degree of adiabaticity and entrainment, precipitation efficiency, and clouddissipating pathways. Combined with a 3-D cloud tracking algorithm (described in detail in PT1), different stages in cloud development within the cloud lifetime are projected onto the CvM space and physically interpreted. Moreover, we show that average CvM space pathways of selected cloud-type subsets are an informative and condensed metric for comparison between different simulations. In PTI we examined how the properties of the initial profiles of the cloud field are reflected in the CvM space. For example, we studied how the inversion layer base height affects the properties of a warm cumulus field (i.e., increasing and decreasing cloudy layer depth). We found a decrease in cloud field adiabaticity and cloud mean area but an increase in cloud thickness and precipitation production with an increase in inversion layer height.

Here (Part II) we use the CvM space to study the coupling between microphysics and dynamics in warm cumulus fields. In section 2 the methodology is described, and in section 3 comparisons between simulations in the CvM space are presented, together with additional analyses of aerosol microphysical and thermodynamical effects on the cloud fields. Section 4 discusses warm cloud invigoration and whether it is consistent with deep convective invigoration followed by a summary in section 5 .

\section{Methods}

Numerical model results in this work are based on the System for Atmospheric Modeling (SAM) Model (version 6.10.3) [Khairoutdinov and Randall, 2003]. Two microphysics schemes are used in this work. The first is an explicit (Spectral) Bin Microphysics (hereafter SBM) scheme [Khain et al., 2004] which has been explained in detail in Part I. The second microphysics scheme is a double moment bulk parameterization [Morrison et al., 2005] (hereafter BULK2M). CVM phase space is used here to test the sensitivities of these two schemes to changes in aerosol concentrations. The BULK2M has no explicit activation scheme; thus, changes in aerosol concentration are manifested by changes in the prescribed cloud droplet concentration. In addition, BULK2M includes saturation adjustment (i.e., all supersaturation is converted to liquid water within a time step), rain sedimentation, and parameterization (Seifert and Beheng) of autoconversion and accretion processes [Seifert and Beheng, 2001]. An additional autoconversion parameterization scheme [Khairoutdinov and Kogan, 2000] was also tested within the BULK2M framework but produced precipitation considerably weaker than expected (from observations, see Figure A1) and hence is not used.

The Barbados Oceanographic and Meteorological Experiment (BOMEX) [Holland and Rasmusson, 1973; Siebesma et al., 2003] was taken as a case study for testing aerosol effects on the clouds. Numerical simulations were set up using a total domain size of $12.8 \mathrm{~km} \times 12.8 \mathrm{~km} \times 4 \mathrm{~km}$ with a grid spacing of $100 \mathrm{~m}$ in the horizontal direction and $40 \mathrm{~m}$ in the vertical direction. Five different levels of aerosol (SBM)/cloud droplet (BULK2M) concentrations $\left(25,50,100,500\right.$, and $\left.2000 \mathrm{~cm}^{-3}\right)$ were simulated for each of the microphysical schemes. For simplicity, we classify the $25 \mathrm{~cm}^{-3}$ simulation as "clean," the $2000 \mathrm{~cm}^{-3}$ simulation as "polluted," and the $100 \mathrm{~cm}^{-3}$ as "intermediate," Additional details on the model setup, cloud tracking algorithm output, and case study initialization parameters can be seen in sections 2 and 3 of PT1. The results from section 3.2 and forth are confined to data between $3 \mathrm{~h}$ (after sufficient spin-up time) and $8 \mathrm{~h}$ (simulation end). 


\section{AGU Journal of Geophysical Research: Atmospheres}

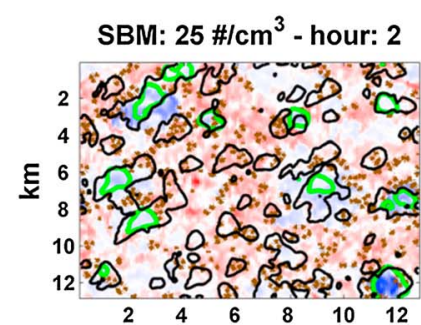

SBM: $25 \# / \mathrm{cm}^{3}$ - hour: 5

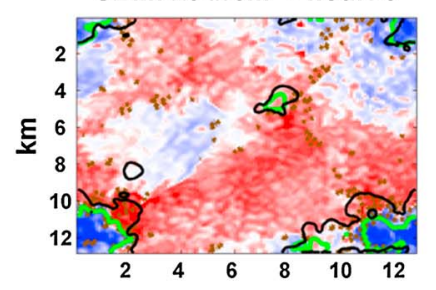

SBM: $25 \# / \mathrm{cm}^{3}$ - hour: 8

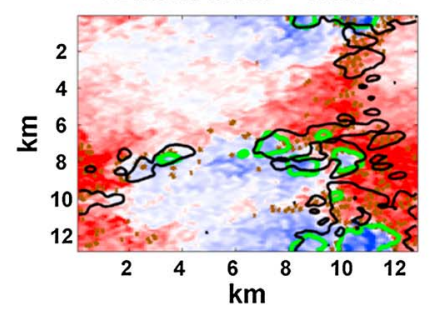

SBM: $100 \# / \mathrm{cm}^{3}$ - hour: 2

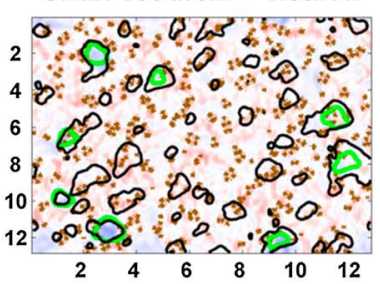

SBM: $100 \# / \mathrm{cm}^{3}$ - hour: 5
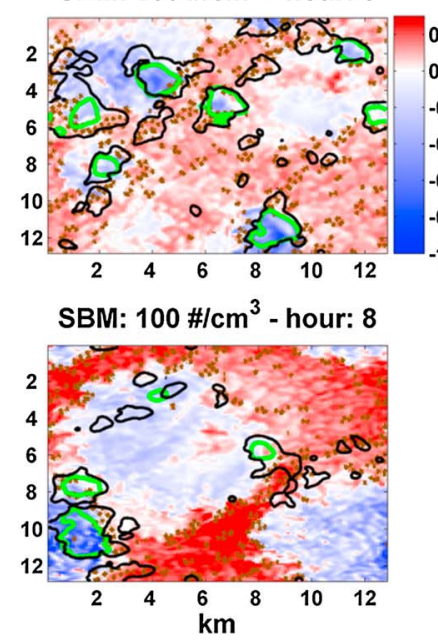

SBM: $2000 \# / \mathrm{cm}^{3}$ - hour: 2

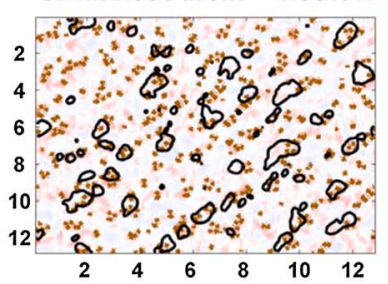

SBM: $2000 \# / \mathrm{cm}^{3}$ - hour: 5

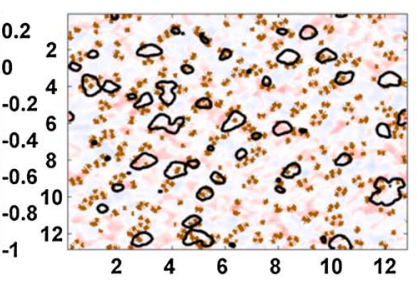

SBM: $2000 \# / \mathrm{cm}^{3}$ - hour: 8

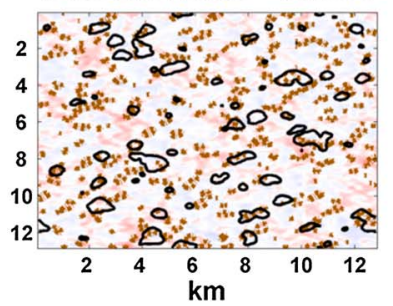

BULK2M: $25 \# / \mathrm{cm}^{3}$ - hour: 2

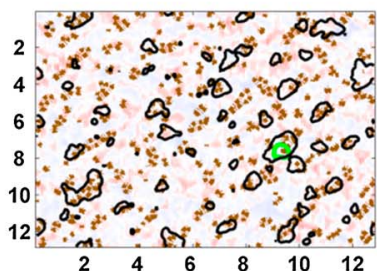

BULK2M: $25 \# / \mathrm{cm}^{3}$ - hour: 5

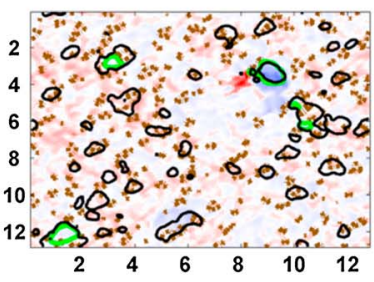

BULK2M: $25 \# / \mathrm{cm}^{3}$ - hour: 8

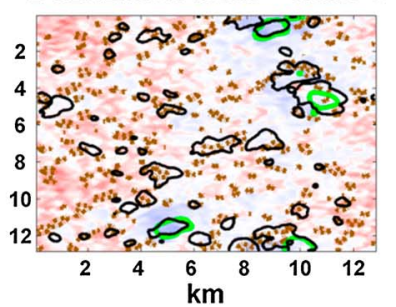

Figure 1. Cloud field snapshots after (top row) $2 \mathrm{~h}$, (middle row) $5 \mathrm{~h}$, and (bottom row) $8 \mathrm{~h}$ of simulation. Four simulation types are presented: $\mathrm{SBM}$ : clean-25 $\mathrm{cm}^{-3}$, intermediate $-100 \mathrm{~cm}^{-3}$, polluted $-2000 \mathrm{~cm}^{-3}$, and BULK2M $-25 \mathrm{~cm}^{-3}$ (as defined in section 2, indicated in the panel titles). Snapshots include cloud cover (black contours, column LWP $>10 \mathrm{~g} / \mathrm{m}^{2}$ ), surface rain (green contours, surface rain mixing ratio $>0.01 \mathrm{~g} / \mathrm{kg}$ ), subcloudy layer updrafts (brown contours, updrafts $>0.5 \mathrm{~m} / \mathrm{s}$ for the mean of the layer between the surface and $480 \mathrm{~m}$ ), and surface level temperature anomalies (color shades, where anomalies are defined as local deviations from the domain mean). Note the emergence of cold pools and clustering of clouds in the SBM clean and intermediate (25 and $100 \mathrm{~cm}^{-3}$ ) simulations, and the similarity between the clean BULK2M and polluted SBM cases.

\section{Results and Discussion}

\subsection{Cloud Field Evolutions}

For giving a general view of the simulated cloud fields and the differences between them, the fields' morphologies and their evolutions are presented first. In Figure 1 three domain snapshots (after 2, 5, and $8 \mathrm{~h}$ ) of cloud liquid water path (LWP), surface precipitation, subcloudy layer updrafts, and surface temperature anomalies are shown for the clean, intermediate, and polluted SBM and clean BULK2M simulations (additional BULK2M cases are shown in Figure A2). The three snapshots represent initial, middle, and final stages in the simulated cloud field evolutions. Clear differences in cloud field organization are seen for the different simulations. Considering the three SBM simulations at $t=2 \mathrm{~h}$, the spatial distributions of clouds are all similar, with increasing surface precipitation seen for decreased aerosol concentrations. The emergence of cold pools is evident below the precipitating clouds. At this stage the subcloudy updrafts are still randomly distributed in all cases.

After $5 \mathrm{~h}$, significant organization is seen in the clean simulation results and to a lesser degree in the intermediate simulation. The domain surface temperature is partitioned to large segments of cold and warm areas, where the coldest areas are located directly below precipitating regions of clouds. This organization is manifested by a reduction in cloud number, increase in cloud size, and clustering of subcloudy layer updrafts, mainly along the boundaries between the warm and cold surface pools. At the end of the simulations at $t=8 \mathrm{~h}$, both the clean and intermediate simulations show a strong partitioning to warm and cold pools at the surface. Again, precipitating clouds are responsible for the creation of cold pools, while the smaller, nonprecipitating cloud forms in clusters along regions of neutral or warm surface temperature anomalies. It can be seen that the large precipitating clouds frequently extend into the warm regions and are supplied by subcloudy layer updrafts located at the cold pool boundaries. 
For the polluted simulation, no surface precipitation or temporal changes in cloud field organization are observed. The clouds and subcloudy layer updrafts maintain similar to the initial spatial distribution, and only minor (compared to the clean and intermediate cases) surface temperature anomalies are seen. The clean BULK2M simulation shows most resemblance with the polluted SBM simulation. The simulated clouds manage to produce weak precipitation that yields weak cold pools with no significant organization. For higher BULK2M cloud droplet concentrations (see Figure A2), no temporal evolution of cloud field organization is seen.

The cloud organization effects seen in Figure 1 (increasing cloud size together with decreasing cloud numbers) with lower aerosol concentrations have been previously reported for warm cumulus field simulations [Xue and Feingold, 2006; Jiang et al., 2009; Seifert and Heus, 2013; Seigel, 2014]. In line with observations [Warner et al., 1979; Zuidema et al., 2012] and simulation results [Xue et al., 2008; Seifert and Heus, 2013; Seigel, 2014], the large surface cold pools induce cloud clustering and limit initiation of new clouds to specific regions (see the organization emergence in time for the clean and intermediate cases in Figure 1). These results imply that precipitation production is the main player in the cloud organization. Indeed, the integrated rain amount varies greatly with aerosol concentration. Taking total domain-accumulated surface rain for the entire simulation, the SBM cases measure $4148,4101,2629,89$, and $2 \mathrm{~mm}$, while the BULK cases measure $680,117,15$, 0 , and $0 \mathrm{~mm}$ for aerosol/cloud droplet concentrations of $25,50,1000,500$, and $2000 \mathrm{~cm}^{-3}$, respectively. Thus, increasing aerosol reduces rain amounts for both microphysical schemes, but the SBM scheme produces 1-2 orders of magnitude more rain. These differences and additional aerosol effects are further explored below.

\subsection{Aerosol Effects on the CrM Space}

In Figure 7 of PT1 we demonstrated how changes in the inversion layer height (conducted on the BOMEX original profile) impact the scatterplot of clouds in the CvM phase space. It was shown that with increasing inversion height, clouds reach larger center of gravity (COG) height and bigger mass values and manage to produce more precipitation but at the expense of a reduction in the adiabaticity level of the clouds in the field. Moreover, differences in inversion height were shown to have little effect on the number and types of clouds produced. Here we examine how changes in aerosol concentration are manifested in the CvM space, using both the morphological and physical classification types for the scatter of clouds (see section 4.2 in PT1 for more details).

Morphological classification divides the cloud population into proto-type (new cloud), split-type (cloud created by splitting event), and merged-type (cloud created by merging event) clouds. In addition, continuous cloud entities (CCEs) were tracked. They represent clouds that keep their identity (i.e., contain more than $75 \%$ of the splitting/merging mass) through insignificant merge and split events. Physical classification divides the cloud population according to cloud base height with respect to the lifting condensation level (LCL) height and whether clouds undergo increase or decrease in cloud top and cloud mass with time. Clouds with bases lower than the domain's minimum LCL are considered precipitating branch clouds; clouds with bases higher than the domain maximum LCL are considered nonreversible dissipating branch clouds, and the rest with bases at the vicinity of $L C L$ are considered either growing branch (show increase in mass, top, or both) or reversible dissipating branch (show temporal decrease in both mass and top) clouds.

In Figure 2, the cloud scatter populations in the CvM space for the 25, 100, and $2000 \mathrm{~cm}^{-3}$ aerosol concentrations using the SBM scheme (Figures $2 \mathrm{a}-2 \mathrm{c}$ and $2 \mathrm{e}-2 \mathrm{~g}$ ) and the $25 \mathrm{~cm}^{-3}$ droplet concentration using the BULK2M scheme (Figures $2 \mathrm{~d}$ and $2 \mathrm{~h}$ ) are examined. Additional concentrations results of BULK2M scheme are shown in Figure $A 3$, showing little changes in the CvM space scatter and bearing most resemblance with the SBM polluted simulation. For the SBM cases, however, significant differences in the CvM space scatter and the branches' relative mass and number percentages (see Figure 2 panel legends) for different aerosol concentrations are seen. We note that the mass percentage indicates the relative amount of water mass (or equivalently cloud sizes) attributed to a specific branch, while the number percentage indicates the relative amount of time spent by the clouds population in that branch. Also included in Figure 2 are the initial (dotted black lines) and final (sold black lines) inversion layer base heights and adiabatic CvM estimations.

The clean run (Figures $2 \mathrm{a}$ and $2 \mathrm{e}, 25 \mathrm{~cm}^{-3}$ ) is completely dominated by the precipitating branch that contains $98.8 \%$ of the total mass but only $15.1 \%$ of the total cloud number. Thus, most of the clouds during most of their lifetime do not precipitate but those that do are by far the largest and most dominant in terms of cloud 


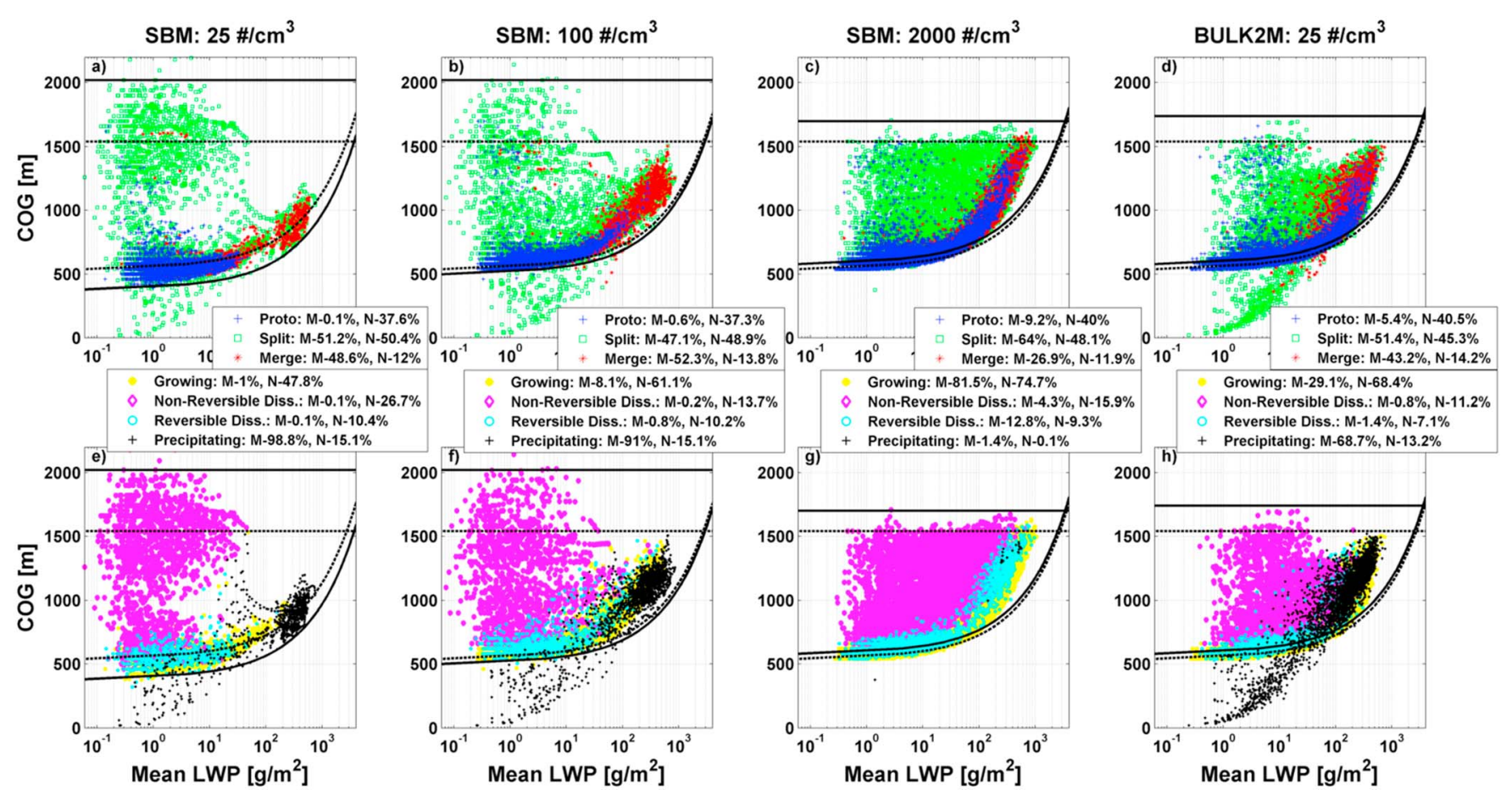

Figure 2. $\operatorname{COG}(\mathrm{m})$ as a function of LWP $\left(\mathrm{g} / \mathrm{m}^{2}\right)$ for all clouds in three $(\mathrm{a}-\mathrm{c}, \mathrm{e}-\mathrm{g}) \mathrm{SBM}$ scheme simulations and the (d and $\left.\mathrm{h}\right)$ BULK2M scheme simulation with $25 \mathrm{~cm}{ }^{-3}$, as indicated by the top panel titles. The adiabatic COG versus LWP estimations (black curves) and inversion layer base heights (horizontal black lines) are shown for initial (dotted lines) and final (solid lines) simulation times. Figures 2a-2d show the Morphological Classification, with blue markers representing proto clouds, red markers for merged clouds, and green markers for split clouds. Figures $2 \mathrm{e}-2 \mathrm{~h}$ show the Physical Classification, with yellow markers representing growing clouds, magenta markers the nonreversible dissipating clouds, cyan markers the reversible dissipating clouds, and black markers the precipitating clouds. Percentage of mass out of total simulation mass and cloud number out of all sampled clouds (at all time steps) for each cloud subset is indicated in the legends.

mass. The precipitating branch is composed about equally of split- and merged-type clouds in terms of mass but dominated by split-type clouds in terms of number (50\% versus $15 \%)$. It can be seen that the adiabatic curve shifted to a lower COG height during the course of the simulation indicating reduction in the LCL height, while the inversion layer base shifted to a higher COG height, indicating upper cloudy-level warming. The domain thermodynamic changes are further discussed in section 3.4.3.

Generally, it can be seen that the entire CVM scatter is confined between the final adiabat and final inversion layer base except for precipitating branch split-type clouds. In PT1 it was shown that the abundance of precipitating branch/split-type clouds residing well below the adiabatic curve is a good indication for the amount of precipitation at the surface. This is due to the fact that the number of precipitating dissipating clouds (with very low COG) and small precipitation segments that typically split off from large precipitating clouds below the $L C L$ are both good precursors to the amount of precipitation reaching the surface. The merged-type clouds in the precipitating branch seem to follow the adiabatic approximation, but since significant sedimentation likely occurs in those clouds it is difficult to use them to assess degree of adiabaticity. The growing branch is relatively limited with respect to both COG and mass values (only $1 \%$ of total mass in simulation, with hardly any COG values above $1 \mathrm{~km}$ ) but still comprises $47.8 \%$ of cloud number. These features indicate the dominance of precipitation processes in this extreme clean simulation that lowers the COG for all masses.

Both dissipating cloud branches are only composed of very small clouds (only $0.1 \%$ of mass each), but clouds spend a significant amount of time in those branches $(10.4 \%, 26.7 \%$ of the reversible, nonreversible dissipating branches, respectively). The nonreversible dissipating branch is populated with split clouds that reach the inversion layer and above, and a major part of it is nearly disconnected from the other branches. The nonreversible dissipating branch is further explored in Figure 3 . The reversible dissipating branch is mainly composed of proto clouds that did not manage to develop much or split clouds that disconnected from larger clouds near the cloud base and lost mass and top height. 
The polluted run (Figures $2 \mathrm{c}$ and $2 \mathrm{~g}, 2000 \mathrm{~cm}^{-3}$ ) shows a very different CvM scatterplot with very little precipitation branch clouds and nearly all clouds residing above the initial adiabatic curve and below the final inversion layer base height. Both the adiabat and inversion layer base show a minor increase in height during the simulation. The growing branch is dominant here both in terms of mass (81.5\%) and number (74.7\%) and reaches high LWP values $\left(>10^{3} \mathrm{~g} / \mathrm{m}^{2}\right.$ ). The proto-type clouds reach much higher masses, indicating less interaction between clouds. Entrainment mixing effects manifest as the deviation of the growing branch from the adiabatic curves (since there is no COG lowering due to sedimentation for the polluted run) and lower effective cloudy layer top height (i.e., the actual height to which many of the small dissipating clouds reach) by $\sim 500 \mathrm{~m}$ than for the clean run. The lower effective cloudy layer top is also due to the fact that the inversion layer base is lower by $\sim 350 \mathrm{~m}$ than the clean run at the end of the simulations. The subspace between the adiabatic curve and the inversion layer height is homogeneously populated with nonreversible ( $4.3 \%$ of mass, $15.9 \%$ of number) and reversible ( $12.8 \%$ of mass, $9.3 \%$ of number) dissipating branch clouds. The homogeneous scatter of these branches is the result of dissipation trajectories of a wide continuum of cloud masses/sizes, either adjacent to the growing branch in the reversible trajectory case or parallel to the $x$ axis for the nonreversible trajectory case.

Although seemingly very similar to the clean run, for most parameters the intermediate concentration (Figures $2 \mathrm{~b}$ and $2 \mathrm{f}, 100 \mathrm{~cm}^{-3}$ ) can be seen as a transition from clean to polluted cases. With increasing aerosol, we see a decrease in the number of high COG_low mass clouds, a decrease in precipitation branch dominance, an increase in COG for large mass clouds, and an increase in the amount of water mass in growing and both dissipating-type branch clouds. The inversion layer base height increases to the same maximum height as for the clean simulation, but the LCL height only shows a minor decrease compared to the clean simulation.

As for the bulk microphysics, the BULK2M $25 \mathrm{~cm}^{-3}$ droplet concentration (Figures $2 \mathrm{~d}$ and $2 \mathrm{~h}$ ) simulation bears similarity with the SBM clean and intermediate simulations with respect to dominance of the precipitating branch and abundance of clouds residing below the adiabats but is similar to the polluted simulation with respect to domain thermodynamic changes and the scatter patterns of the growing, reversible, and nonreversible dissipating branches. The lower amount of total mass attributed to the precipitating branch using BULK2M in comparison with SBM (both using $25 \mathrm{~cm}^{-3}$ ) indicates a lower efficiency of precipitating processes for the BULK2M scheme. Generally, it can be seen (Figure A3) that BULK2M results as presented on the CvM phase space show much lower sensitivity to droplet concentration compared with the SBM results. The comparison between BULK2M and SBM schemes is further discussed in section 3.4.

We note that based on Figure 2, two opposing conclusions regarding aerosol effects on COG can be reached. On the one hand, if all clouds are considered, then low aerosol concentration simulations show the highest COG values. On the other hand, if only large mass clouds are considered (merged clouds for example), we see the highest COG for high concentration simulations. This indicates the importance of looking at the entire CvM phase space population for a full understanding of this complex aerosol-cloud field system.

In section 4.2.3 of PT1 we found that there are two preferred pathways for nonreversible dissipating branch clouds. (i) Gradual dissipation-slow rising of cloud base with loss of mass (mainly by evaporation), as seen by the nonreversible dissipating trajectories in Figure 4a of PT1. (ii) Direct creation of small mass fragments that are torn away from the upper part of clouds and have high COG and relatively small mass. The dissipating branches of the SBM polluted and clean simulations (see Figure 3) are extreme examples of cases where the former and latter pathways of dissipation dominate, respectively.

From the density plot (Figure 3a) we can see that the clean case has two separate focal point locations for dissipation. One is for low COG $(\sim 750 \mathrm{~m})$ and small masses, presumably small, short-lived clouds that form from the growing branch (represented by the red dashed lines) but do not manage to develop, since they follow nonreversible dissipating trajectory type I. The second is located at high COG $(1500 \mathrm{~m})$ and small masses and represents the shedding of small fragment clouds near the tops of the large, long-lived precipitating clouds (at the inversion layer) having nonreversible dissipating trajectory type II. This was confirmed by manual tracking the parent clouds of the highest COG split clouds. These split clouds evaporate slowly due to large drop sizes, so they densely populate the area near the inversion layer. These findings are supported by Figures $3 \mathrm{~b}$ and $3 \mathrm{c}$ that show that most dissipating clouds are of small thickness $(<300 \mathrm{~m})$ and either have very low altitude base or very high base. In this case no gradual dissipating of large clouds via rising cloud base is seen. 


\section{AGU Journal of Geophysical Research: Atmospheres}
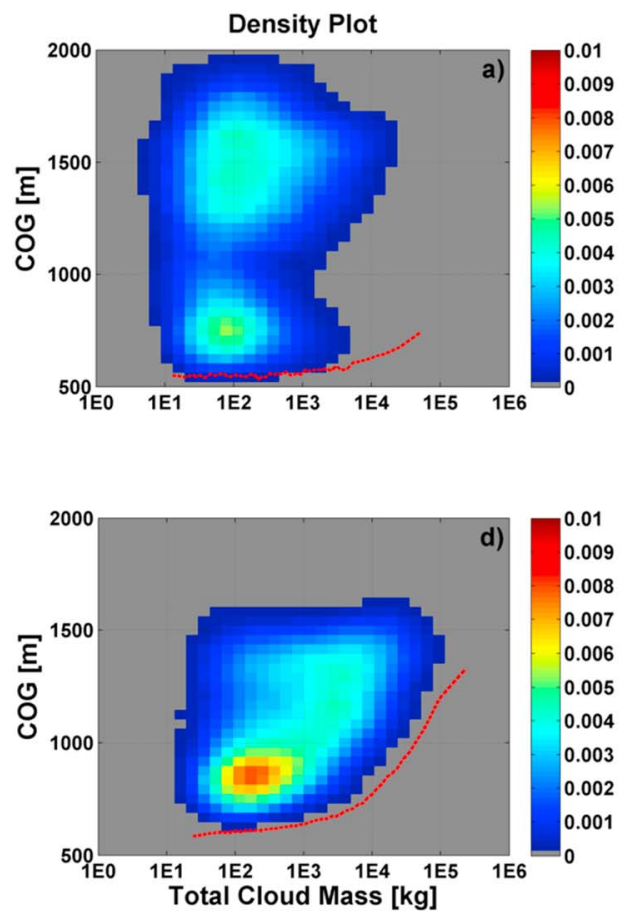
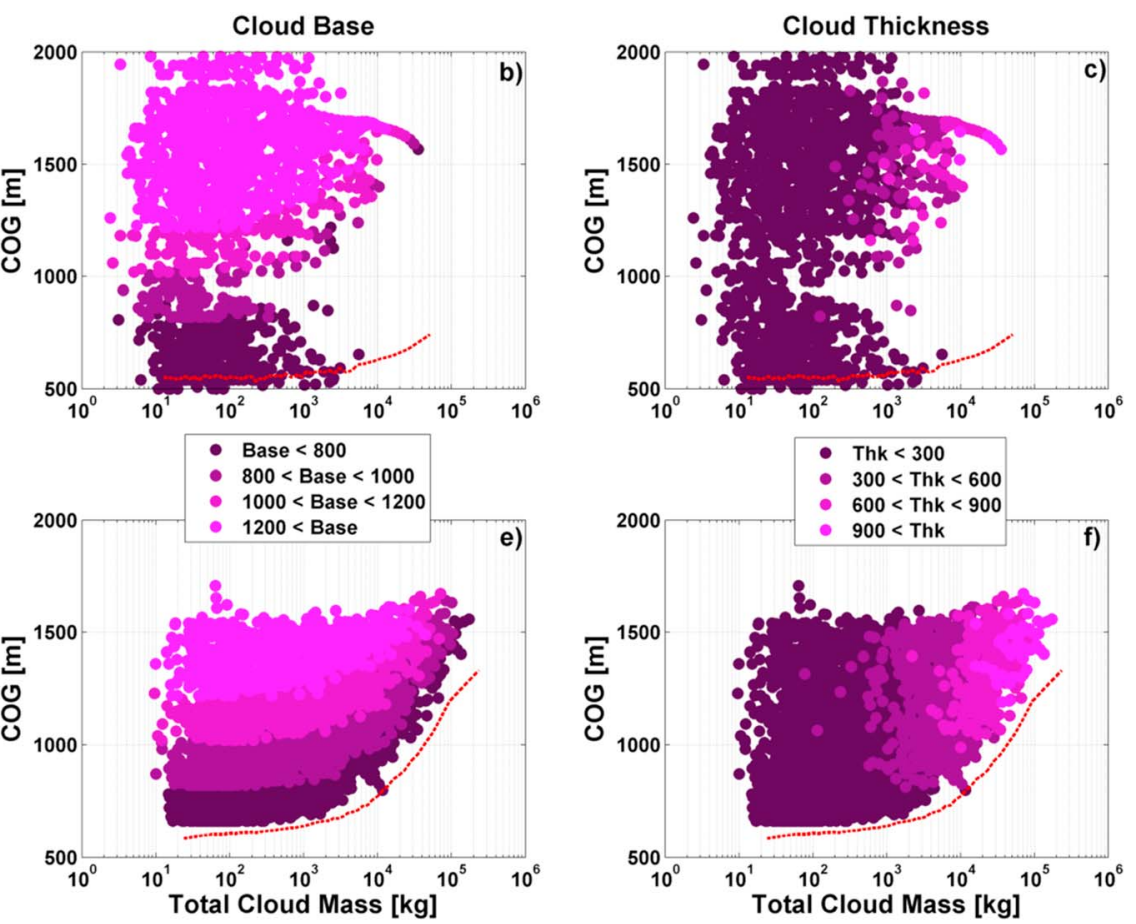

Figure 3. Nonreversible dissipating branch cloud analysis in the CvM space, for the SBM clean-25 $\mathrm{cm}^{-3}$ (Figures $3 a-3 c$ ) and polluted-2000 $\mathrm{cm}^{-3}$ (Figures $3 \mathrm{~d}-3 \mathrm{f}$ ) simulations. ( $a, d)$ Normalized density plots. (b, e) Clouds sorted by base heights values, as described in panel legend. (c, f) Clouds sorted by vertical thickness, as described in panel legend. Red dashed lines show the average growing branch locations.

The density, cloud base, and thickness plots for the polluted case (Figures $3 \mathrm{~d}-3 \mathrm{f}$ ) are more homogeneous. Like the clean case, the nonreversible dissipating branch is still dominated by a maximum at COG $\sim 750 \mathrm{~m}$ that represents all the small clouds that live for a few minutes and dissipate at low COG. However, the rest of the CvM space is densely populated by nonreversible dissipating clouds that originated from the growing branch. In this case the clouds occupy all cloud base heights and thickness values, indicating that the gradual dissipation of clouds located all along the growing branch clouds dominates (i.e., nonreversible dissipating trajectory type I), since when a growing branch cloud loses mass with minor change to $\mathrm{COG}$, its thickness decreases and its base tends to increase in height (as seen in Figures $3 e$ and 3f).

\subsection{Comparison of Average Curves}

The first question when presenting an average CvM space curve is what subset of clouds do we want to average? Since the average is performed with respect to mass, a subset with minimum variance in COG per mass value is beneficial for comparison of several simulations together. As seen in section 4.2.3 of PT1, averages of the growing branch, proto and merged clouds, or continuous cloud entities (CCEs, described in section 3.2 of this work and in section 3 of PT1) may all give similar results, with the growing branch being the favored subset when comparison with the adiabatic approximation is desired. However, from Figure 2 it is clear that the growing branch is only representative of the polluted case, as opposed to the clean case where the majority of the mass is associated with the precipitating branch, which in turn is nonexistent in the polluted case. Thus, to capture both the majority of cloud mass and a significant part of the cloud lifetime, we focus on the proto- and merged-type subsets of clouds, which typically occupy both the growing branch and the large mass regions of the precipitating branch (see Figure 2). We also use total mass $(\mathrm{kg})$ (instead of LWP $\left(\mathrm{g} / \mathrm{m}^{2}\right)$ ) for the $x$ axis to get a better representation for the full range of cloud sizes.

The average CvM curves for all aerosol concentrations for the SBM and BULK2M schemes are displayed as solid lines in Figure 4 (shades for standard deviations). Superimposed as well are the average CCE curves (dashed lines). Hereafter, we consider both the 25 and $50 \mathrm{~cm}^{-3}$ simulations as clean, the $100 \mathrm{~cm}^{-3}$ as 

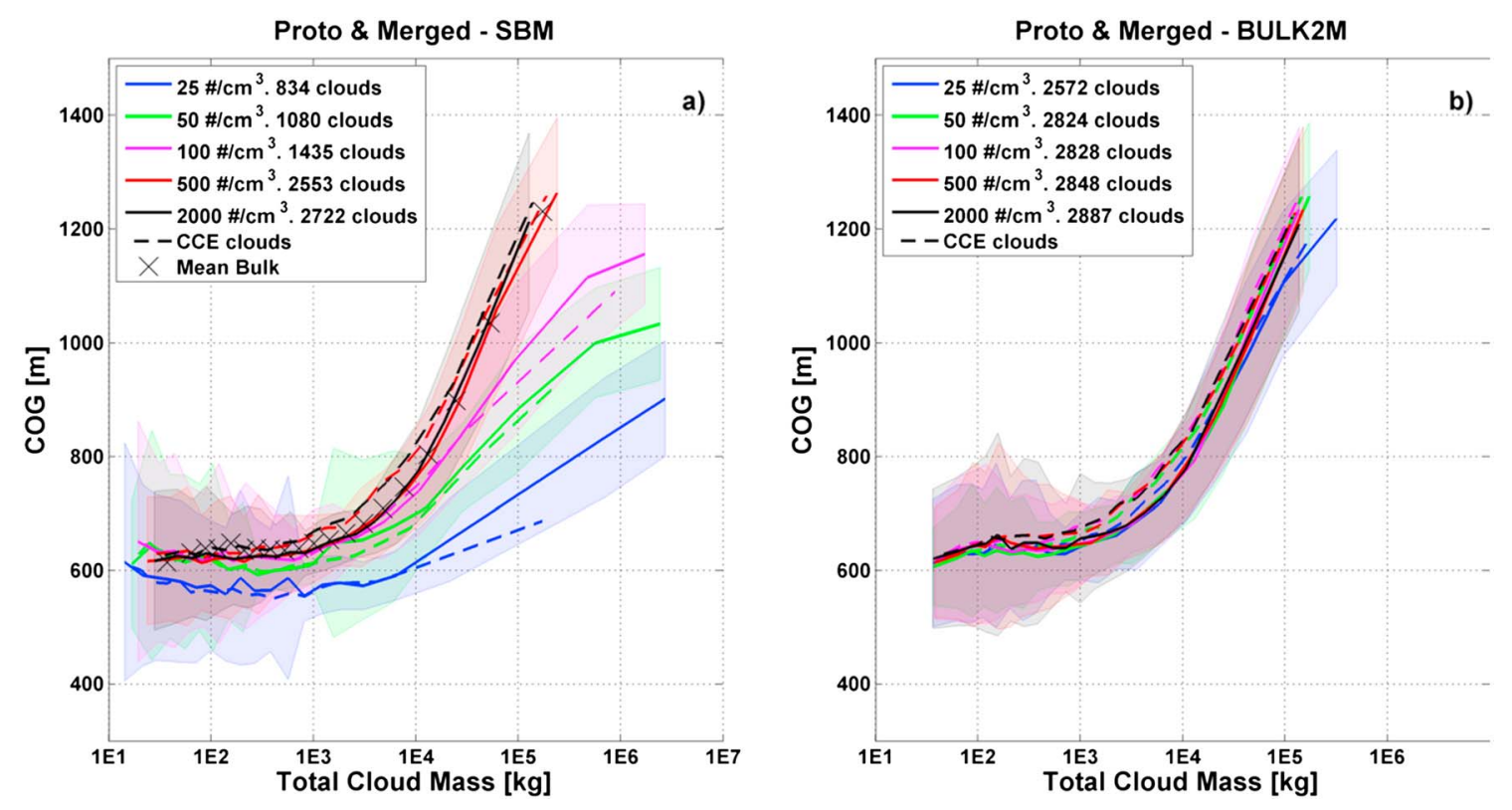

Figure 4. Aerosol effects on average curves for proto and merged cloud-type subsets (solid lines and shades represent their corresponding standard deviations) and CCE cloud subset (dashed lines). (a) Bin (SBM) microphysical scheme. (b) Bulk (BULK2M) microphysical scheme. Color coding and number of proto and merged clouds per aerosol concentration are included in panel legends. The average of the bulk microphysics curve is added (black plus markers) in Figure 4a for reference. For high aerosol concentrations $\left(>500 \mathrm{~cm}^{-3}\right.$ ), both bin and bulk schemes converge to the same curve in the CvM space.

intermediate, and both the 500 and $2000 \mathrm{~cm}^{-3}$ simulations as polluted. In agreement with Figure 2, we find consistent differences between the average curves using the SBM scheme (Figure 4a). As aerosol concentrations increase, the mean cloud COG curve is located higher in the CvM domain. This implies that a greater portion of the cloud water mass is located higher in the atmosphere for the higher aerosol concentration cases. Higher aerosol concentrations also yield larger standard deviations of COG per mass value. Additionally, it can be seen that increasing aerosol amount results in a significant increase in the number of clouds produced in the simulation from 657 proto and merged clouds in the cleanest simulation to 2220 proto and merged clouds in the most polluted simulation (see numbers in Figure 4a), resulting from substantial effects on the organization of the field (see Figure 1). These organization effects (i.e., cloud clustering) may also be the reason why lower aerosol concentrations simulations yield higher maximum cloud mass values (as can be seen in Figure 4a). Saturation of the simulated aerosol effect above a certain aerosol concentration $\left(>500 \mathrm{~cm}^{-3}\right.$ in Figure $\left.4 \mathrm{a}\right)$ is seen, where any addition of aerosol has no further effect on the average cloud curve in the CVM space.

In contrast to the SBM scheme, only minor aerosol effects are apparent when using BULK2M scheme ( Figure $4 \mathrm{~b}$ and consistent with Figures 1, 2, A2, and A3). For all five aerosol concentrations, we find nearly identical average curves on the CvM space and hardly any difference in cloud numbers. Only the $25 \mathrm{~cm}^{-3}$ BULK2M simulation has a significantly lower number of proto and merged clouds (similar to the $500 \mathrm{~cm}^{-3}$ SBM run), and its average curve deviates to slightly lower COG values than the rest for high mass values. The differences between bin and bulk schemes in cloud resolving models have been recently discussed in depth [Khain et al., 2015]. The constraint on the shape and type of the size distributions [e.g., Ovchinnikov et al., 2014], commonly used saturation adjustment to $100 \%$ relative humidity [e.g., Tao et al., 1989], parameterization of autoconversion from cloud to rain drop [e.g., Gilmore and Straka, 2008], and approximations in the sedimentation process were pointed out as fundamental sources of differences between the two-moment bulk and bin schemes [Khain et al., 2015]. When plotting the average bulk scheme curve on the bin scheme space (black plus markers, Figure 4a), we find that it coincides with the polluted $\left(500\right.$ to $2000 \mathrm{~cm}^{-3}$ ) bin simulations, i.e., results from all bulk simulations correspond to the scenario in bin simulations where aerosol concentrations are very large and the microphysical effect saturates, with all excess vapor condensing on liquid drops [Xue and Feingold, 2006; Khain et al., 2015]. 
For the BULK2M and polluted SBM cases the average CCE curves give a good representation of the proto and merged cloud subset, showing the same range of masses and slightly higher COG due to the inclusion of high COG_-low mass dissipating split clouds. For the clean and intermediate $\operatorname{SBM}$ cases $\left(25,50\right.$, and $\left.100 \mathrm{~cm}^{-3}\right)$, the average CCE curves increasingly miss the large end of masses and show lower COG values. This fact, together with large cloud entities seen in Figure 1, indicates that the large clouds in these cases are formed by significant merging events that are not represented by the CCEs (i.e., clustering of large clouds, none of which contain above $75 \%$ of the total merged mass). The fact that the average CCE curve for the BULK2M $25 \mathrm{~cm}^{-3}$ simulation spans the entire range of masses covered by the proto and merged cloud subset is another indication that significant clustering (i.e., merging and splitting of large cloud entities) does not occur when using the bulk scheme.

\subsection{Further Analysis of Aerosol Induced COG Increase}

As a demonstration of the capabilities of using both the CvM phase space and automated 3-D cloud tracking, we examine the potential reasons for the increase in the COG with increasing aerosol seen with the SBM scheme. We note that various processes may combine to create clouds with higher COG but we look into three main effects:

1. Reduced COG due to sedimentation. The clean cases (with abundant precipitation) are more likely to be affected by significant sedimentation of rain mass that lowers the total water mass COG.

2. In-cloud processes during the cloud growing stage. In the polluted cases the overall droplet surface area of numerous smaller droplets is much larger than the clean ones allowing for higher condensation efficiency. As the collision-coalescence efficiency is reduced and precipitation processes are delayed this stage is further prolonged [Squires, 1958; Kogan and Martin, 1994; Xue and Feingold, 2006; Khain, 2009; Dagan et al., 2015b]. The droplets can be pushed higher in the atmosphere due to stronger updrafts (more latent heat release) [Kogan and Martin, 1994] and larger droplet mobility measured by smaller effective terminal velocity [Koren et al., 2014, 2015].

3. Cloud field-scale feedbacks resulting from aerosol effects on cloud evolution influencing the environment in which subsequent clouds grow (i.e., thermodynamic preconditioning). Changes in aerosol loading impact the amount of precipitation reaching the surface and subsequently alter the conditions in the subcloud layer which "feeds" the clouds [Xue et al., 2008; Seifert and Heus, 2013; Seigel, 2014]. Moreover, an increase in aerosol loading may increase cloudy layer entrainment and evaporation rates around the margins and tops of clouds [Xue and Feingold, 2006; Stevens, 2007; Seigel, 2014]. A buffering mechanism was suggested [Stevens and Feingold, 2009] whereby the aerosol suppression of precipitation results in more evaporation of cloud in the inversion layer and subsequent deeper growth of clouds that might offset the rainfall suppression. More generally, aerosol effects on phase changes and precipitation result in vertical redistribution of heat and moisture, which may either stabilize or destabilize the environment in which subsequent clouds grow [Seifert and Heus, 2013].

Because we focus on the growing and mature stages in the lifecycle of clouds, all analyses in this section are performed on the proto- and merged-type subsets of clouds.

3.4.1. Sedimentation Effects on COG

Here we test how significant is sedimentation in reducing COG for clean cases. In Figure 5a we plot the cloud mean effective terminal velocity $(|\eta|(\mathrm{m} / \mathrm{s}))$ as function of total cloud mass. $\eta$ is defined as the mass-weighted terminal velocity (always of negative sign) of all the drops within a given volume [Koren et al., 2015]. A larger $|\eta|$ indicates that a greater portion of the cloud mass comprises large drops, for which sedimentation becomes more significant. A clear correlation with the aerosol concentrations is shown. Larger concentration dictates smaller $|\eta|$ except for clouds with the very large mass. A clear separation in the $|\eta|$ trend is shown between the precipitating and nonprecipitating concentrations. When precipitation processes are suppressed (for aerosol concentration $\geq 500 \mathrm{~cm}^{-3}$ ) $|\eta|$ remains small for all cloud masses.

To follow the overall vertical motion of cloud mass, we plot the mass-weighted cloud mean absolute velocity $\left(V_{\mathrm{abs}}(\mathrm{m} / \mathrm{s})\right)$ as a function of total mass (see more information in Koren et al., [2015]) (Figure 5b). The absolute velocity is defined as $V_{\text {abs }}=W+\eta$, where $W$ is the air vertical velocity. If $V_{\text {abs }}>0$, the COG of the cloud mass is ascending. For small cloud masses $\left(<10^{4} \mathrm{~kg}\right)$ all cases show positive $V_{\mathrm{abs}}$, indicating little if any sedimentation. For large cloud masses the polluted cases show an increase in $V_{\mathrm{abs}}$, while the clean and intermediate 

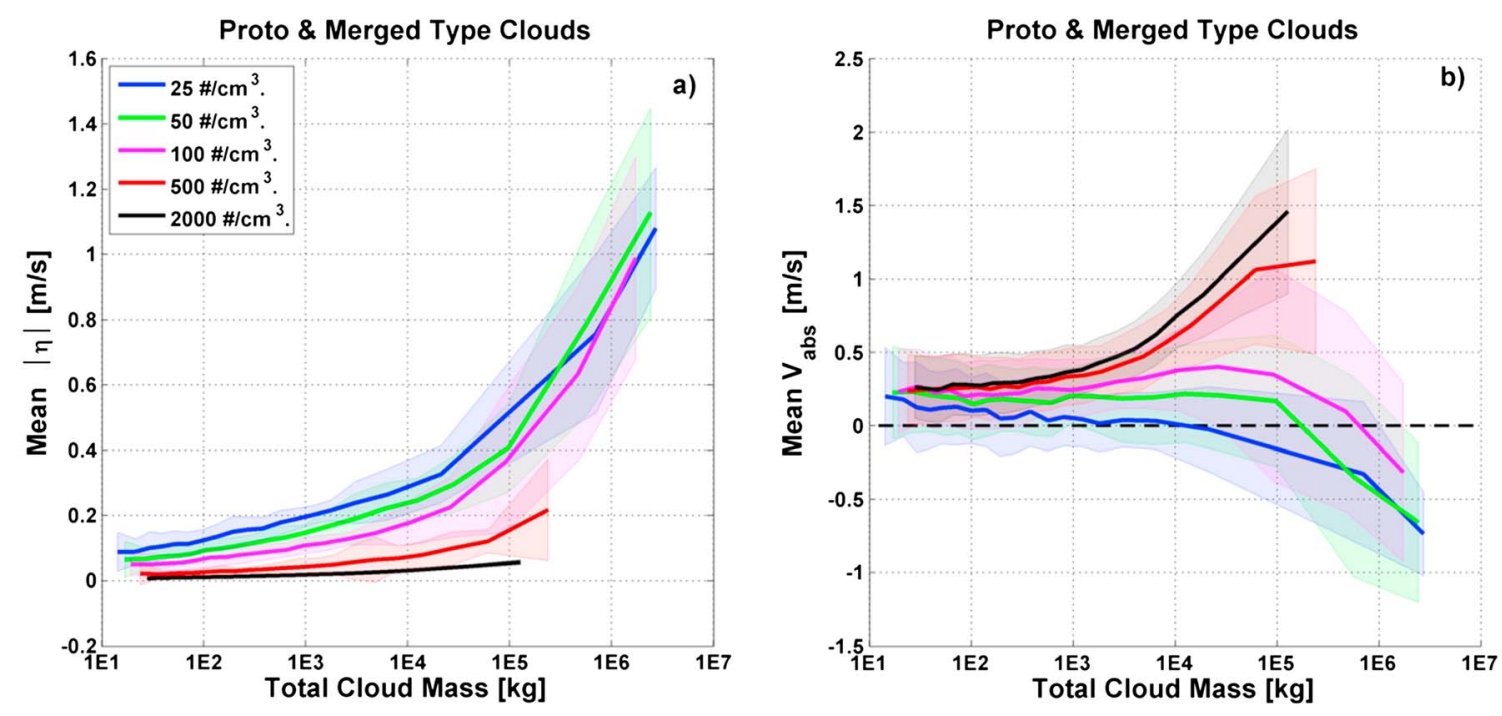

Figure 5. Mean proto- and merged-type cloud mass-weighted velocities sorted by cloud total mass ( $\mathrm{kg}$ ). Velocities include the following: (a) absolute value of cloud effective terminal velocity $-|\eta|(\mathrm{m} / \mathrm{s})$ and $(\mathrm{b})$ cloud absolute velocity $-V_{\mathrm{abs}}(\mathrm{m} / \mathrm{s})$.

cases show a decrease in $V_{\text {abs }}$ and reach negative values for the highest masses. Again, a clear separation in $V_{\text {abs }}$ is seen between the different simulations, with higher aerosol concentrations yielding higher $V_{\text {abs }}$ for most mass values. It can therefore be concluded that sedimentation has a strong effect on lowering the total mass COG with decreasing aerosol concentration. Nevertheless, $V_{\text {abs }}$ reflects both sedimentation and cloud dynamics (i.e., vertical velocity) which may have a strong effect as well.

\subsubsection{In-Cloud Effects on COG}

In Figure 6 we sort by total cloud mass the following parameters: cloud area, cloud base and top height, condensation rate, LWC, and maximum and average vertical velocities. Figure 6 a shows how per mass value, the clean cases have larger cloud area than polluted cases (see also Figure 1). As previously mentioned and seen in Figures 1 and 4, cloud clustering due to cold pools can explain why the clean cases produce larger clouds ( 2 orders of magnitude difference in maximum cloud area and maximum cloud mass) than the polluted cases.

In Figure $6 \mathrm{~b}$, cloud base and top height are analyzed. For smaller clouds (masses $<10^{4} \mathrm{~kg}$ ), we find only minor differences (within the model's vertical resolution) between the cloud base and top heights in the different simulations, except for the $25 \mathrm{~cm}^{-3}$ simulation, which shows lower base and top heights. For larger clouds (masses $>10^{4} \mathrm{~kg}$ ), the clean and intermediate simulations generally show a decrease in cloud base due to rain that is significant for the largest clouds, but the polluted cases show higher cloud top height per mass value. It is important to note that up to masses of $\sim 2 \times 10^{5} \mathrm{~kg}$ (maximum mass for polluted cases), the larger the aerosol concentration, the higher is the average cloud top and base. Moreover, for that mass range the vertical separation in cloud tops is more significant and starts for lower masses than the vertical separation in cloud bases, clearly showing deepening of the polluted clouds.

For the clean cases, the lower bases for larger clouds can be explained by the abundant precipitation and sedimentation of water. It may also be due to lower average LCL heights in the clean cases from frequent precipitation that significantly cools and humidifies the subcloud layer (see Figure 7). The high peak mass values can be attributed to clustering of clouds and creation of very large cloud entities. The higher peak cloud top heights can be explained by several factors as will be shown below. However, it is easy to see that peak cloud top values for each aerosol concentration correspond nicely to the final domain inversion layer base heights, as shown in Figures 2 and 7.

In agreement with the findings above, in Figure $6 c$ we generally see a monotonic separation (per cloud mass value) of vertical velocity magnitudes with respect to aerosol concentrations; the higher the concentration, the larger the average and maximum cloud vertical velocity values. Moreover, the larger the cloud mass, the larger the separation. The separation in vertical velocities is generally only apparent for larger clouds 

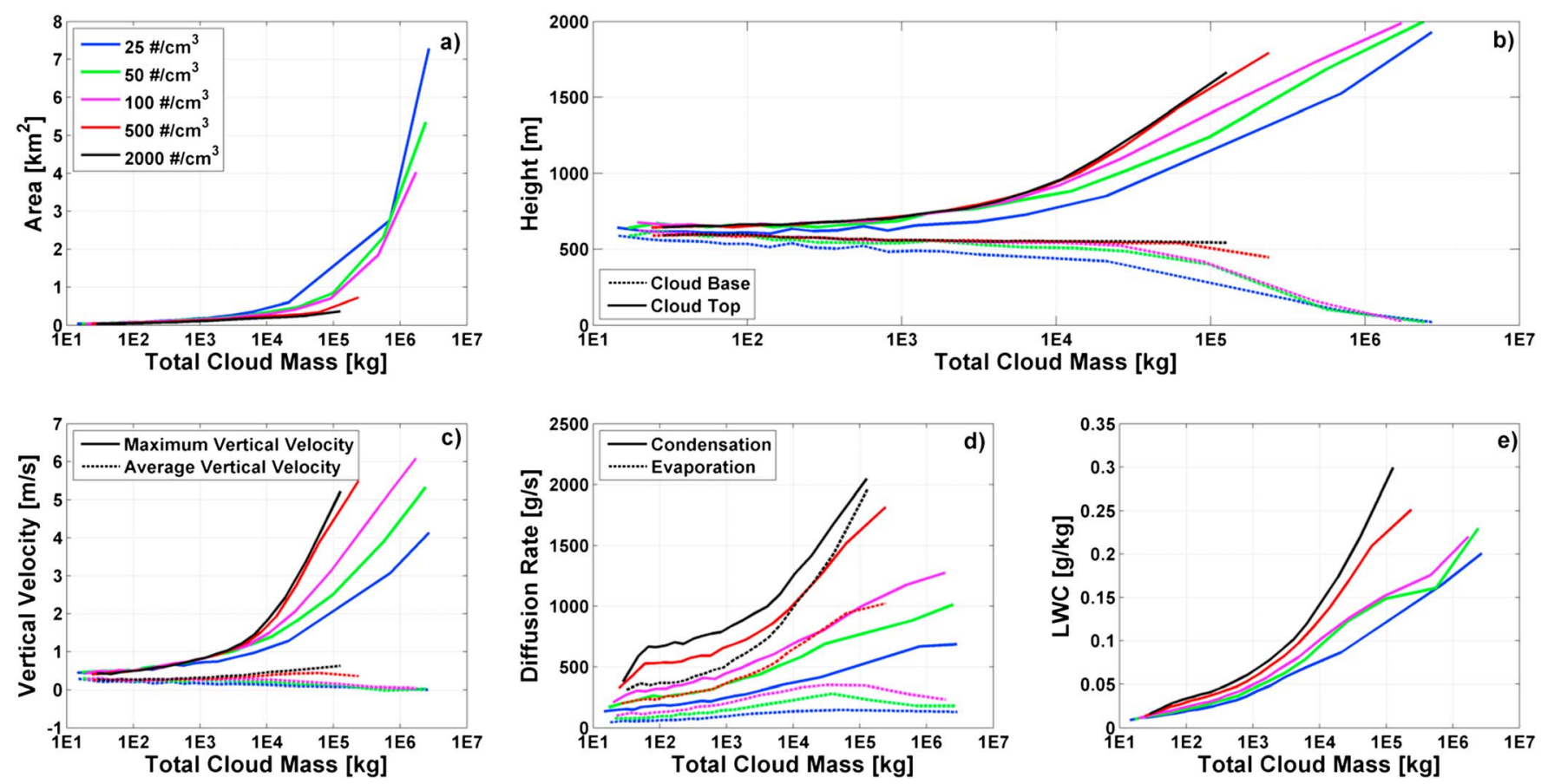

Figure 6. Analysis of selected proto- and merged-type cloud parameters as a function of total cloud mass ((kg), for different aerosol concentrations (only SBM) simulations. (a) Cloud average horizontal cross-sectional area $\left(\mathrm{km}^{2}\right)$. (b) Cloud base and top height ((m), bold solid lines. (c) Cloud maximum (solid lines) and average (dashed lines) vertical velocities (m/s). (d) Cloud average condensation (solid lines) and evaporation (dashed lines) rates (g/s). (e) Cloud average liquid water content (LWC $(\mathrm{g} / \mathrm{kg})$ ).

(masses $>10^{4} \mathrm{~kg}$ ), but the differences are very small for average velocities $\mathrm{O}(0.1 \mathrm{~m} / \mathrm{s}$ ) and much larger for maximum vertical velocities $\mathrm{O}(1 \mathrm{~m} / \mathrm{s})$. These differences indicate that higher vertical velocities are another main reason for higher COG in the polluted cases.

We note that if all masses are considered, the intermediate $\left(100 \mathrm{~cm}^{-3}\right)$ simulation exhibits the largest maximum vertical velocities but not the largest average vertical velocities. The peak in maximum vertical velocities may be due to a beneficial combination of (i) the delay in precipitation processes compared to the clean cases, (ii) increased release of latent heat compared to the clean cases (further explained below), (iii) higher inversion layer base compared to polluted cases, and (iv) less entrainment than for the polluted cases. This "optimal" concentration has been recently discussed [Dagan et al., 2015b]. The fact that this peak is not reflected in the average vertical velocity can be explained by the large sizes of cloud clusters formed in the intermediate simulation (see Figures 1 and 6a) which may include passive regions with low updraft values.

In Figure $6 \mathrm{~d}$, absolute values of cloud mean condensation and evaporation rates $(\mathrm{g} / \mathrm{s})$ are shown, respectively. For all cases and all masses the mean condensation rates are larger than the mean evaporation rates, and higher aerosol concentration yields higher condensation/evaporation rates. For the polluted cases, condensation and evaporation rates rise with cloud mass, but the $500(2000) \mathrm{cm}^{-3}$ simulation shows an increase (reduction) in the difference between mean condensation and evaporation (i.e., net condensation) with mass, possibly due to enhanced evaporation efficiencies at the cloud edges for the higher concentration. The clean and intermediate cases also show monotonic increase in condensation rates with cloud mass. Their evaporation rates, however, show an increase with mass for low masses $(<1 \mathrm{E} 4 \mathrm{~kg}$ ) and a decrease for the larger masses, indicating weak evaporation occurring at the edges of large clean clouds. Although not showing the highest condensation/evaporation rates, the intermediate simulation $\left(100 \mathrm{~cm}^{-3}\right)$ shows the maximum net condensation for the larger cloud mass. This aerosol concentration drives an optimal balance between higher condensation in the clouds' cores (compared to the clean cases) and lower evaporation at the clouds' edges (compared to the polluted cases).

Lastly, mean LWC (g/kg) values (Figure 6e) show a monotonic increase with increasing cloud mass and higher (per cloud mass) values for higher aerosol concentrations. The higher condensation rates, combined with smaller sizes and the smaller effective terminal velocities $(\eta)$ can explain how larger mean LWC values and 


\section{AGU Journal of Geophysical Research: Atmospheres}
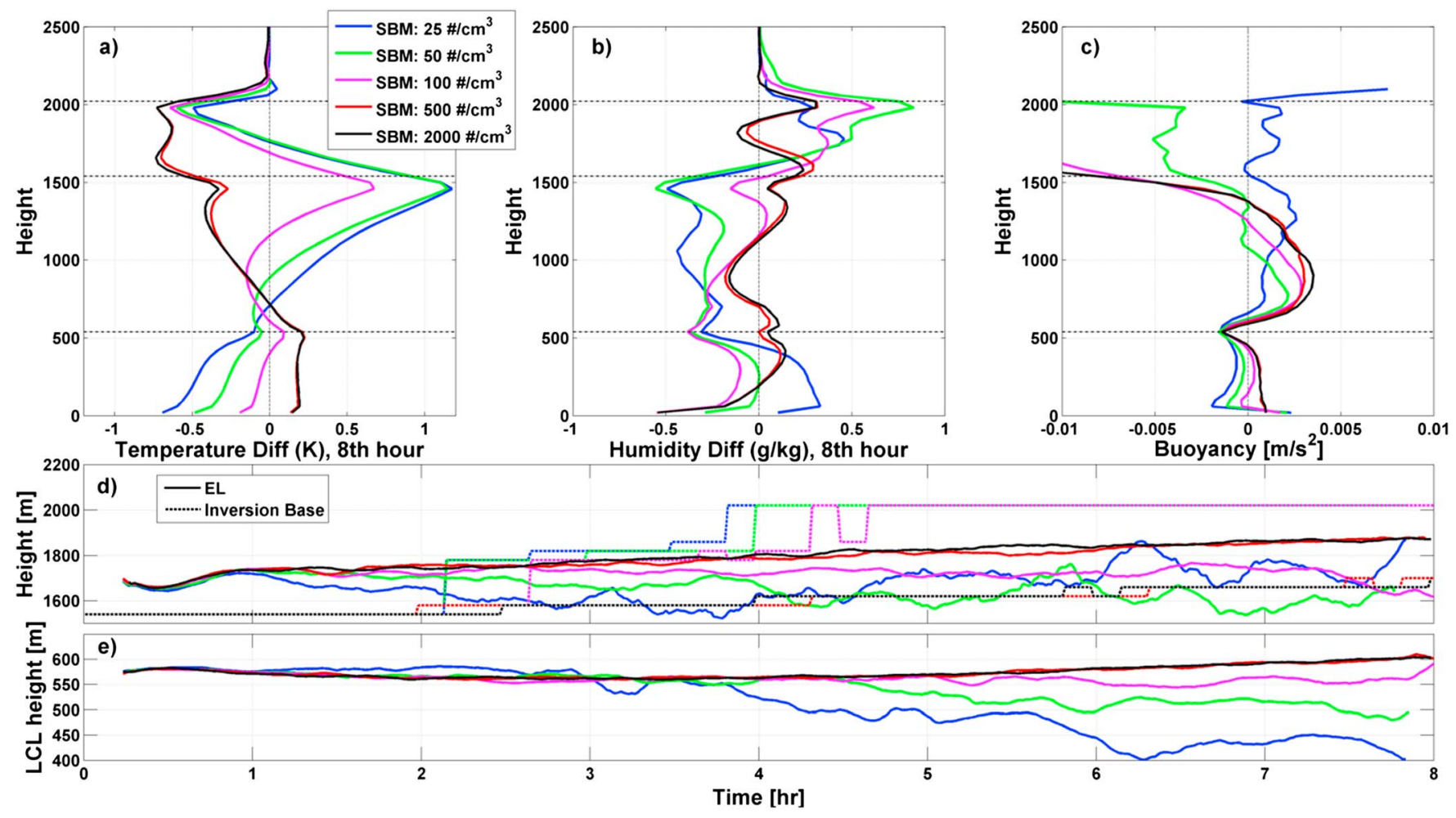

Figure 7. Differences in mean domain (a) temperature and (b) humidity vertical profiles, for different aerosol concentration simulations (see legend). Values represent subtraction of mean profile during the final hour of simulation from the initial profile. (c) Mean buoyancy profiles within and below the cloud cores of the top $10 \%$ most massive clouds for each simulation. Included are horizontal dash-dotted lines, representing from bottom to top, the initial profile LCL, inversion layer base, and top heights. (d) Time series of inversion layer base heights (dashed lines) and equilibrium level heights (EL-solid lines). (e) Time series of lifting condensation level (LCL) heights. 
the inversion layer we see drying (moistening) for the polluted (clean) simulations. The subcloudy layer shows consistent moistening only for the cleanest simulation.

As seen in Figure 2, the domain mean thermodynamic profile changes are manifested by changes in the LCL and inversion layer base heights. Time series of the domain mean $L C L$, equilibrium level (EL, the first height above the level of free convection where a parcel's moist adiabatic temperature is equal to that of the environment), and inversion layer base are shown in Figures $7 \mathrm{~d}$ and $7 \mathrm{e}$. The $\mathrm{LCL}$ and EL are calculated as the mean of all domain profile LCLs and ELs. Since in many cases single profile (per column) inversion layers did not exist, the inversion was calculated by first taking the domain mean temperature profile and then finding the first level of temperature increase with height. For the clean simulations a continuous decrease of the mean LCL height with time is seen, with the lowest concentration showing the lowest $L C L$ heights $(\sim 160 \mathrm{~m}$ decrease during $8 \mathrm{~h})$. The polluted simulations show a minor increase in $\mathrm{LCL}$ height with time $(\sim 40 \mathrm{~m})$ and are nearly identical to each other. The intermediate simulation shows relatively constant $L C L$ height. The inversion layer base response to aerosol is even stronger, with an increase of $\sim 500 \mathrm{~m}$ for the clean and intermediate simulations and $\mathrm{a} \sim 150 \mathrm{~m}$ increase for the polluted simulations. The lower the aerosol concentration, the faster these changes occur (e.g., $2 \mathrm{~h}$ for the $25 \mathrm{~cm}^{-3}$ simulation compared with $3 \mathrm{~h}$ for the $100 \mathrm{~cm}^{-3}$ simulation).

The mean domain EL height does not behave like the inversion layer base height. The polluted simulations show a steady EL increase from $1700 \mathrm{~m}$ to $\sim 1850 \mathrm{~m}$, while the clean and intermediate simulations EL heights fluctuate strongly (increased amplitude with decreasing aerosol concentrations-probably due to field organization effects) between 1500 and $1850 \mathrm{~m}$, usually staying lower than the polluted cases' EL heights. By comparing the upper COG extent of the cloud scatter in Figure 2 with Figure $7 \mathrm{~d}$, it can be concluded that the inversion layer base serves as a better measure for the effective cloudy layer top than the equilibrium level (EL) height.

The changes seen in Figures $7 a, 7 b, 7 d$, and 7e demonstrate the significant imprint of precipitation processes on domain thermodynamics, as previously reported [Xue and Feingold, 2006; Xue et al., 2008; Seifert and Heus, 2013]. The clean simulations that precipitate experience more warming of the cloudy layer and a greater depletion of moisture (i.e., release of latent heat during condensation with reduced local evaporation) which raises the inversion layer base, together with a moistening and cooling of the subcloudy layer due to evaporation of falling precipitation, which lowers the LCL height. The moistening of the inversion layer for clean cases is due to the evaporation of many small cloud fragments from the large cloud clusters at those levels. The polluted simulations precipitate very little and hence moisten and cool most of the cloudy layer due to evaporation, with only slight warming near the cloud base where most of the condensation occurs. The polluted cases are relatively stable thermodynamically, with minor increases in the $\mathrm{LCL}, \mathrm{EL}$, and inversion base heights. The vertically averaged cooling seen for the polluted cases is due to larger cooling rates (i.e., via evaporation) compared with those expected by the BOMEX large-scale forcing.

As a summary for the aerosol effects on domain thermodynamics and cloud microphysics, the mean cloud core buoyancy profiles $\left(\mathrm{m} / \mathrm{s}^{2}\right)$ are plotted (Figure $7 \mathrm{c}$ ), comprising the top $10 \%$ most massive clouds for each of the simulations. Buoyancy is based on differences of potential temperature, water vapor, and liquid water between cloudy voxels (liquid water content above $0.005 \mathrm{~g} \mathrm{~kg}^{-1}$ ) and noncloudy ones, for each vertical level (see Appendix B of PT1 for details). Cloud cores are defined as cloud voxels with vertical velocity above $0.25 \mathrm{~m} / \mathrm{s}$. Subcloud core profiles (in case there is no precipitation that reaches the ground) are based on the profiles which reside below the cloud base core voxels. In the subcloud layer (below the LCL), the precipitating clean cases show negative buoyancy, while nonprecipitating cases show slightly positive buoyancy. Within the cloudy layer (above the LCL and below the inversion layer base) all simulations generally show positive buoyancy, with the polluted cases showing significantly higher buoyancy, consistent with the higher condensation rates and vertical velocities, and more unstable thermodynamic profiles seen above.

Within the inversion layer, polluted case buoyancy decreases to large negative values, showing that the inversion base is still very strong for these cases. The $50 \mathrm{~cm}^{-3}$ and $100 \mathrm{~cm}^{-3}$ simulations show more modest decreases in buoyancy within the inversion layer, and the $25 \mathrm{~cm}^{-3}$ simulation shows a slight increase in buoyancy values. The large cloud clusters and low aerosol concentration in the latter case maintain very high in-cloud vapor mixing ratios (high supersaturation in the cores), so that cloudy air is positively buoyant even though it is cooler than the environment. 


\section{Discussion on Warm Cloud Invigoration}

The findings described in the sections above imply that with increasing aerosol concentration, both changes in the microphysical processes of clouds and consequent changes in the environmental conditions combine to increase COG during the clouds' growing stages. The separation of the aerosol effects studied here to sedimentation, in-cloud processes, and environmental preconditioning is rather artificial, since all these effects are coupled. The higher COG in the polluted environment is the end result of a chain of processes and feedbacks taking place from the cloud scale up to the cloud field scale.

This increase in COG can be interpreted as an invigoration effect, which has been previously defined as a deepening of clouds due to increased aerosol concentrations. Here when simulations are compared per cloud total mass value (equivalent to cloud development and lifetime), we indeed observe cloud deepening. Moreover, the larger vertical velocities, condensation rates, LWC, buoyancies, and environmental profile instability observed for the polluted clouds are all in agreement with cloud growth intensification processes associated with invigoration. A distinct difference, however, is that these shallow warm clouds are not accompanied by stronger rainfall. This may indicate that the potential for more rain from cloud deepening (as previously suggested by Stevens and Seifert [2008], Stevens and Feingold [2009], and Seifert et al. [2015]) in the BOMEX case is not sufficient to offset the aerosol microphysical suppression within a simulation time span of $8 \mathrm{~h}$.

This can be further explained by a recent work [Dagan et al., 2015b] that has shown that each cloud parameter (e.g., mass, size, and accumulated surface rainfall) has a corresponding optimal aerosol concentration, which yields maximum values. This optimal concentration is strongly dependent on the environmental settings (thermodynamic potential) and generally increases with increasing thermodynamic potential (deeper clouds). Therefore, one should expect different end results for each cloud parameter for deep convective versus shallow cumulus clouds. Specifically, in the BOMEX case, the optimal concentration for rainfall may be even lower than $25 \mathrm{~cm}^{-3}$.

We stress the fact that the peak values in cloud size and mass observed for the clean clouds are due to completely different processes (i.e., cloud clustering) that are generally not associated with cloud invigoration. The significant cloud clustering for clean may be especially pronounced in numerical models due to limited domain sizes and periodic boundary conditions. We also note that as opposed to the deep convective case, the warm shallow cumulus clouds are typically capped by a strong inversion, which may also significantly alter the field organization and cloud responses to changes in aerosol concentrations.

\section{Summary}

In the second part of this two-paper series, the objective was to study aerosol effects on warm cumulus cloud fields using the COG versus Mass (CVM) phase space (introduced in Part I) and a new cloud tracking algorithm. We find that substantial microphysical effects can be detected on the CvM phase space only when an explicit bin microphysics scheme (i.e., SBM) is used, as opposed to the bulk scheme (i.e., BULK2M) which was found to show weak sensitivity to changes in droplet concentration (Figures $4 a, A 2$, and A3). Moreover, the average CvM curves using the bulk scheme are identical to polluted average curves using the bin scheme, which in turn show saturation of the aerosol effect at such high concentrations. These findings may be due to the saturation adjustment method commonly used in bulk schemes and to less efficient precipitation production, as previously suggested [Lebo and Seinfeld, 2011; Milbrandt and Morrison, 2012; Khain et al., 2015$].$

Using the bin scheme, aerosol effects seen here include among others: (1) higher COG with increasing aerosol concentrations for all growing branch and large mass precipitating branch clouds, (2) increase in domain water mass and cloud number attributed to precipitating branch clouds for decreasing aerosol concentrations, (3) prevalence of shedding of small clouds from larger clouds as the main dissipation mechanism for the clean (precipitating) cases versus gradually dissipating cloud via rising cloud base as the main mechanism for polluted (nonprecipitating) cases, (4) clustering (merging events) of clouds increases with decreasing aerosol concentration due to increasing size and prevalence of cold pools, and (5) larger decrease (increase) in LCL (inversion base) height with time as aerosol concentration decreases.

Here we have examined average proto and merged cloud subset curves that represent mainly the growing and mature stages of the clouds and include the majority of water mass for all simulations. Other types or subsets of cloud types can be averaged as well (such as short/long lifetime clouds and clouds that reach or 
do not reach the inversion layer), each encompassing its own set of information. The choice of cloud type (proto, split, merged, growing, precipitating, or dissipating) or cloud parameter (such as cloud top, maximum mass, and COG) is elemental to the outcome of an analysis regarding a microphysical effect on clouds.

We propose that the increased COG with increase in aerosol concentration here is driven by three main (coupled) processes: (1) the delay in precipitation processes, (2) the more efficient condensation, and (3) the smaller effective terminal velocity $(\eta)$, which all combine to prolong and intensify vertical growth for polluted clouds and alter the clouds' impact on the environmental conditions that subsequently feedback on the clouds. For the clean simulations $\left(25,50 \mathrm{~cm}^{-3}\right)$, rapid precipitation initiation together with increased sedimentation leads to accumulation of water mass at lower heights. Moreover, precipitation falling below the cloud base causes cloudenvironment feedbacks, which alter the thermodynamic conditions (lower LCL and cloud base) and also promote cloud clustering that creates the largest cloud entities (in terms of peak cloud area and depth). These clustering effects may be amplified in numerical simulations due to the homogeneous conditions and periodic boundary conditions which force the domain to self-organize. Hence, it is crucial to test if these effects are as prominent in nature where synoptic gradients and diurnal cycles constantly perturb the system.

For the polluted simulations $\left(500,2000 \mathrm{~cm}^{-3}\right)$, delay in the precipitation processes together with increasing condensation rates, decreasing $|\eta|$ values, and destabilization of the thermodynamic profile enables the clouds' COG to reach higher with larger buoyancy values and larger vertical velocities, and reduced water sedimentation. The increase in cloud COG with aerosol increase seen here can be interpreted as an invigoration effect on warm clouds for clouds with similar mass is in agreement with some previous observational studies for warm convective clouds [Kaufman et al., 2005; Yuan et al., 2011; Koren et al., 2014]. Some of the key processes typically linked to deep convective invigoration [Tao et al., 2012; Altaratz et al., 2014] are also observed in this work. Others are different, for example, the deeper and more polluted vigorous warm cumulus clouds are caped by strong inversions and therefore did not reach vertical development that enables the production of stronger precipitation. We expect that indications of warm cloud invigoration should increasingly resemble the deep convective invigoration ones as environmental conditions are modified to support thicker warm clouds (i.e., higher inversion layer base) than the BOMEX case study.

\section{Appendix A: Morrison Double Moment Scheme (BULK2M)}

The bulk BULK2M scheme has two options for parameterization of autoconversion and accretion processes: KK [Khairoutdinov and Kogan, 2000] and SB [Seifert and Beheng, 2001]. Both parameterizations were tested

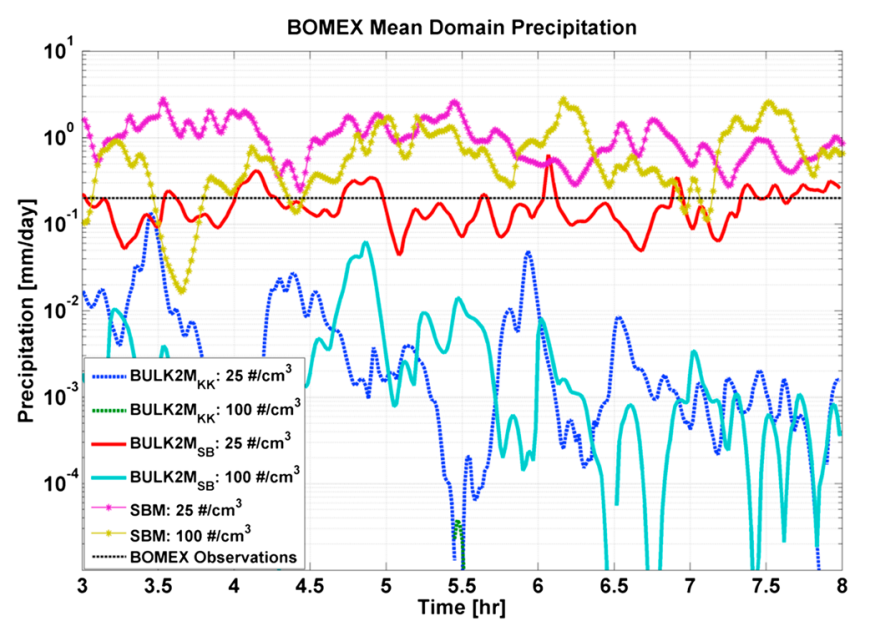

Figure A1. Time series of mean domain precipitation rates ( $\mathrm{mm} /$ day) (between 3 and $8 \mathrm{~h}$ ), for different microphysical schemes and $25,100 \mathrm{~cm}^{-3}$ droplet concentrations. Schemes include (as defined in the text) BULK2M with KK parameterization (BULK2 $\mathrm{M}_{\mathrm{KK}}$-dashed lines), BULK2M with SB parameterization (BULK2M $\mathrm{M}_{\mathrm{SB}}$ - bold solid lines), and SBM (solid lines with asterisks). Precipitation estimation based on in situ measurements is added as well (black horizontal dashed line). (together with the SBM scheme) for their ability to produce warm rain in BOMEX simulations (see Figure A1) and to see how they compare with estimations of rain from in situ measurements [Holland and Rasmusson, 1973]. For a droplet concentration of $25 \mathrm{~cm}^{-3}$, it can be seen that the SB parameterization produces at least an order of magnitude more rain than the $\mathrm{KK}$ parameterization. The bin SBM scheme is the most efficient for warm rain production and yields about an order of magnitude more than the BULK2M scheme with the SB parameterization. For the $100 \mathrm{~cm}^{-3}$ simulations, the difference between these two schemes increases to 2 orders of magnitude, while the KK parameterization produces no surface precipitation at all. Both the BULK2M $\mathrm{SB}_{\mathrm{SB}}-25 \mathrm{~cm}^{-3}$ and 
BULK2M: $25 \# / \mathrm{cm}^{3}$ - hour: 2

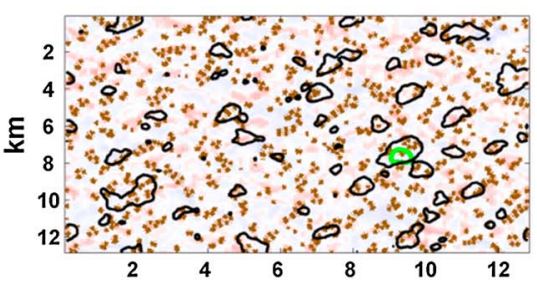

BULK2M: $25 \# / \mathrm{cm}^{3}$ - hour: 5

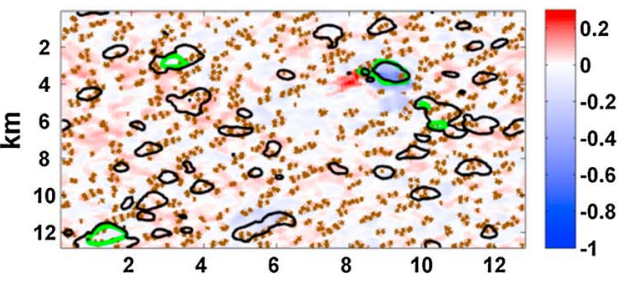

BULK2M: $25 \# / \mathrm{cm}^{3}$ - hour: 8

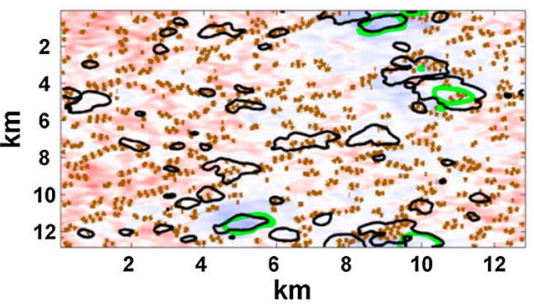

BULK2M: $100 \# / \mathrm{cm}^{3}$ - hour: 2

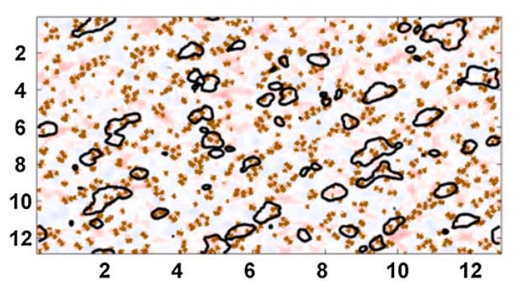

BULK2M: $100 \# / \mathrm{cm}^{3}$ - hour: 5

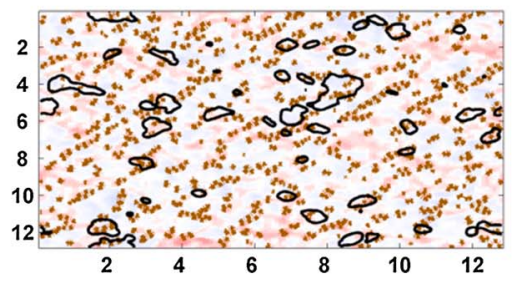

BULK2M: 100 \#/cm ${ }^{3}$ - hour: 8

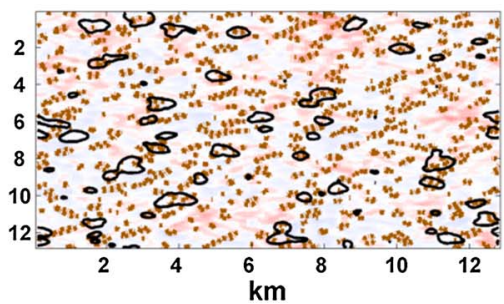

BULK2M: $2000 \# / \mathrm{cm}^{3}$ - hour: 2

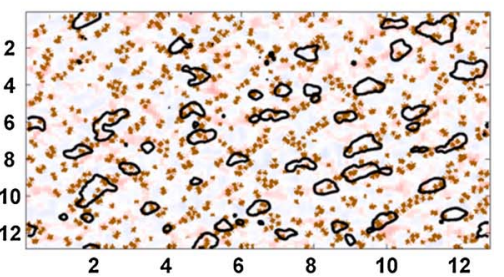

BULK2M: $2000 \# / \mathrm{cm}^{3}$ - hour: 5

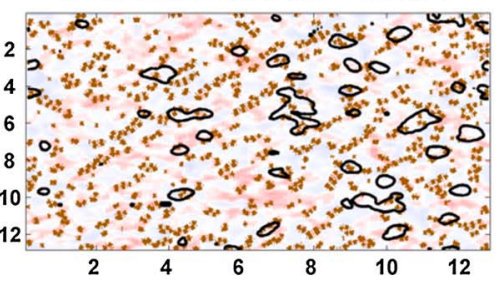

BULK2M: $2000 \# / \mathrm{cm}^{3}$ - hour: 8

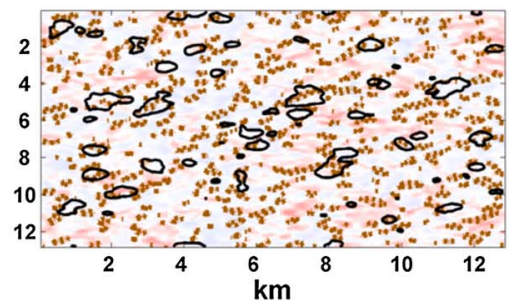

Figure A2. Same as Figure 1 but using BULK2M microphysics with Seifert and Beheng autoconversion scheme, for three representative droplet concentrations $\left(25,100\right.$, and $2000 \mathrm{~cm}^{-3}$, as labeled in panel titles).
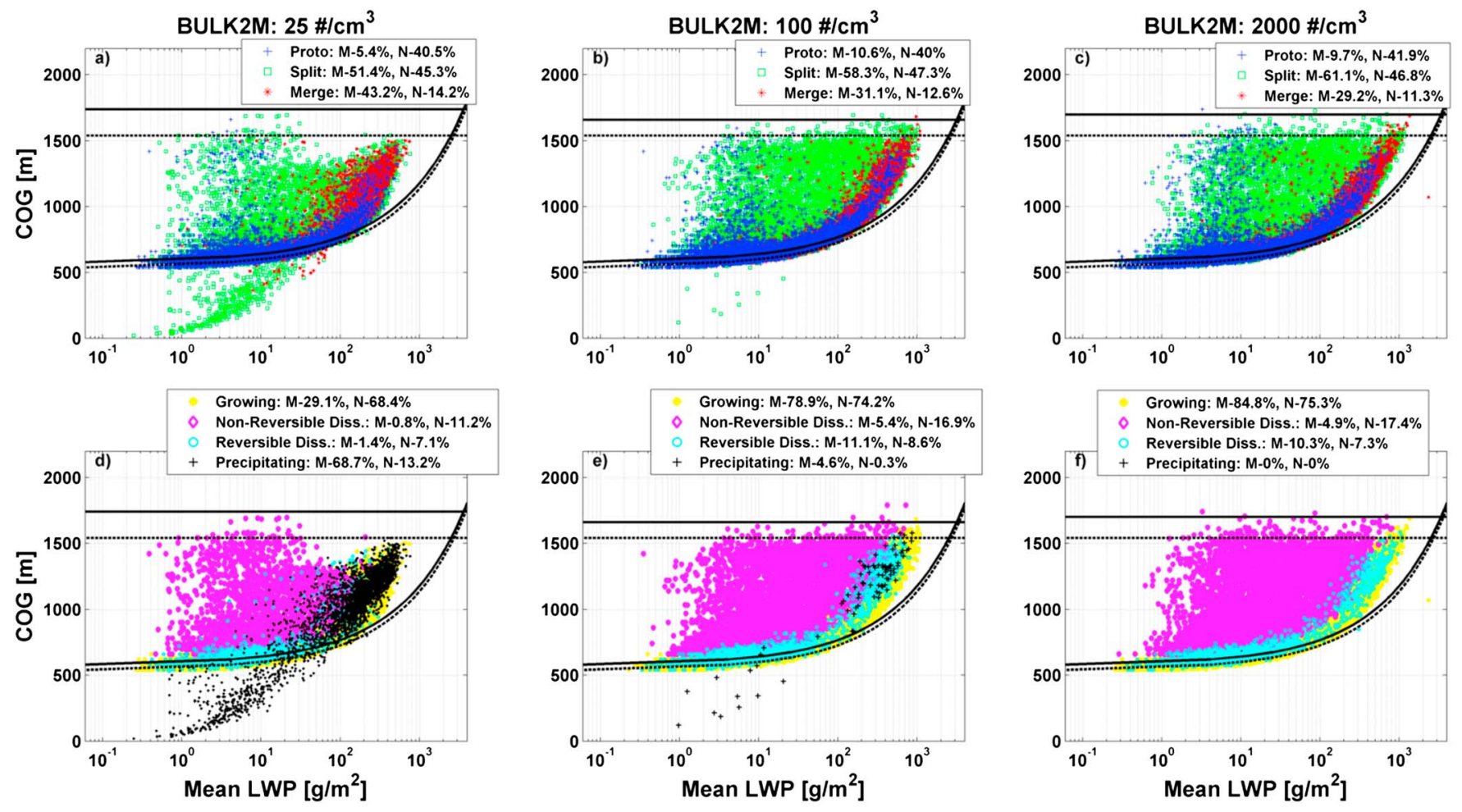

Figure A3. Same as Figure 2 but using only BULK2M microphysics with Seifert and Beheng autoconversion scheme, for three representative droplet concentrations $\left(25,100\right.$, and $2000 \mathrm{~cm}^{-3}$, as labeled in panel titles). 
$\mathrm{SBM}-100 \mathrm{~cm}^{-3}$ compare well with the BOMEX observational precipitation estimation (black dashed line). Due to these results, we chose the SB parameterization for BULK2M scheme in this work. We recognize that the recently published rain parameterization for cumulus clouds [Kogan and Mechem, 2013] may be worth exploring in the future.

The cloud field evolutions of representative clean, intermediate, and polluted BULK2M simulations are shown in Figure A2 (see Figure 1 in the main text for interpretation). As seen in Figure 1, weak indications of cold pool formation and cloud field self-organization are seen for the clean simulation, which is the only BULK2M simulation that produces significant precipitation. Such effects are completely absent in the other BULK2M simulations, which show relatively constant cloud field characteristics for the entire time span of the simulations.

The cloud distribution on the CVM space for representative clean, intermediate, and polluted BULK2M simulations $\left(25,100\right.$, and $2000 \mathrm{~cm}^{-3}$ droplet concentrations) is presented in Figure $A 3$ (for figure interpretation, see Figure 2 in the main text). In comparison with the substantial differences seen in Figures 2 and 3 in the main text, more minor differences are seen between the BULK2M simulations. Only the clean simulation $\left(25 \mathrm{~cm}^{-3}\right)$ produces significant precipitation but in amounts comparable to the intermediate and polluted cases using Spectral Bin Microphysics (SBM). Similar to Figure A2, we generally see lower sensitivity of CvM phase space patterns to changes in droplet concentrations using the BULK2M scheme compared to SBM.

\section{Acknowledgments}

The research leading to these results has received funding from the European Research Council under the European Union's Seventh Framework Programme (FP7/2007-2013)/ERC grant agreement 306965. M.O. and G.F.'s contributions are supported in part by the U.S. Department of Energy, Office of Science, Biological and Environmental Research under the Atmospheric System Research (ASR) Program. Pacific Northwest National Laboratory is operated by Battelle for the U.S. Department of Energy under contract DE-AC0676RLO1830. A.B.K. was supported, in part, by NSF AGS-1119164. The authors acknowledge Marat Khairoutdinov for making SAM model available for this study, available at http://rossby.msrc. sunysb.edu/ marat/SAM.html. The SBM microphysics scheme was developed and implemented by A.P.K. and M.O. We thank the HPC staff in Weizmann computer center for helping with technical modeling issues and the anonymous reviewers for their contribution to this work.

\section{References}

Albrecht, B. A. (1989), Aerosols, cloud microphysics, and fractional cloudiness, Science (New York, NY), 245(4923), 1227-1230, doi:10.1126/ science.245.4923.1227.

Altaratz, O., I. Koren, L. A. Remer, and E. Hirsch (2014), Review: Cloud invigoration by aerosols-Coupling between microphysics and dynamics, Atmos. Res., 140-141(0), 38-60, doi:10.1016/j.atmosres.2014.01.009.

Andreae, M. O., D. Rosenfeld, P. Artaxo, A. A. Costa, G. P. Frank, K. M. Longo, and M. A. Silva-Dias (2004), Smoking rain clouds over the Amazon, Science, 303(5662), 1337-1342, doi:10.1126/science.1092779.

Dagan, G., I. Koren, and O. Altaratz (2015a), Aerosol effects on the timing of warm rain processes, Geophys. Res. Lett, 42, 4590-4598, doi:10.1002/2015GL063839.

Dagan, G., I. Koren, and O. Altaratz (2015b), Competition between core and periphery-based processes in warm convective clouds-From invigoration to suppression, Atmos. Chem. Phys., 15(5), 2749-2760, doi:10.5194/acp-15-2749-2015.

Gilmore, M. S., and J. M. Straka (2008), The Berry and Reinhardt autoconversion parameterization: A digest, J. Appl. Meteorol. Climatol., 47(2), 375-396, doi:10.1175/2007JAMC1573.1.

Grabowski, W. W., et al. (2006), Daytime convective development over land: A model intercomparison based on LBA observations, Q. J. R. Meteorol. Soc., 132(615), 317-344, doi:10.1256/qj.04.147.

Heiblum, R. H., et al. (2016), Characterization of cumulus cloud fields using trajectories in the center-of-gravity vs. water mass phase space: 1. Cloud tracking and phase space description, J. Geophys. Res. Atmos., 121, doi:10.1002/2015JD024186.

Holland, J. Z., and E. M. Rasmusson (1973), Measurements of the atmospheric mass, energy, and momentum budgets over a 500-kilometer square of tropical ocean, Mon. Weather Rev., 101(1), 44-55, doi:10.1175/1520-0493(1973)101<0044:MOTAME>2.3.CO;2.

Intergovernmental Panel on Climate Change (2013), Clouds and aerosols, in Climate Change 2013-The Physical Science Basis, edited, pp. 571-658, Cambridge Univ. Press, doi:10.1017/СBO9781107415324.016.

Jiang, H., and G. Feingold (2006), Effect of aerosol on warm convective clouds: Aerosol-cloud-surface flux feedbacks in a new coupled large eddy model, J. Geophys. Res., 111, D01202, doi:10.1029/2005JD006138.

Jiang, H., H. W. Xue, A. Teller, G. Feingold, and Z. Levin (2006), Aerosol effects on the lifetime of shallow cumulus, Geophys, Res. Lett., 33, L14806, doi:10.1029/2006GL026024.

Jiang, H., G. Feingold, and I. Koren (2009), Effect of aerosol on trade cumulus cloud morphology, J. Geophys. Res., 114, D11209, doi:10.1029/ 2009JD011750.

Kaufman, Y. J., I. Koren, L. A. Remer, D. Rosenfeld, and Y. Rudich (2005), The effect of smoke, dust, and pollution aerosol on shallow cloud development over the Atlantic Ocean, Proc. Natl. Acad. Sci. U.S.A., 102(32), 11,207-11,212, doi:10.1073/pnas.0505191102.

Khain, A. P. (2009), Notes on state-of-the-art investigations of aerosol effects on precipitation: A critical review, Environ. Res. Lett., 4(1), 015004, doi:10.1088/1748-9326/4/1/015004.

Khain, A. P., A. Pokrovsky, M. Pinsky, A. Seifert, and V. Phillips (2004), Simulation of effects of atmospheric aerosols on deep turbulent convective clouds using a spectral microphysics mixed-phase cumulus cloud model. Part I: Model description and possible applications, J. Atmos. Sci., 61(24), 2963-2982, doi:10.1175/JAS-3350.1.

Khain, A. P., D. Rosenfeld, and A. Pokrovsky (2005), Aerosol impact on the dynamics and microphysics of deep convective clouds, $Q$. J. $R$. Meteorol. Soc., 131(611), 2639-2663, doi:10.1256/qj.04.62.

Khain, A. P., et al. (2015), Representation of microphysical processes in cloud-resolving models: Spectral (bin) microphysics versus bulk parameterization, Rev. Geophys., 53, 247-322, doi:10.1002/2014RG000468.

Khairoutdinov, M. F., and Y. L. Kogan (2000), A new cloud physics parameterization in a large-eddy simulation model of marine stratocumulus, Mon. Weather Rev., 128(1), 229-243, doi:10.1175/1520-0493(2000)128<0229:ANCPPI>2.0.CO;2.

Khairoutdinov, M. F., and D. A. Randall (2003), Cloud resolving modeling of the ARM summer 1997 IOP: Model formulation, results, uncertainties, and sensitivities, J. Atmos. Sci., 60(4), 607-625, doi:10.1175/1520-0469(2003)060<0607:CRMOTA >2.0.CO;2.

Kogan, Y. L., and W. J. Martin (1994), Parameterization of bulk condensation in numerical cloud models, J. Atmos. Sci., 51(12), 1728-1739, doi:10.1175/1520-0469(1994)051<1728:POBCIN>2.0.CO;2.

Kogan, Y. L., and D. B. Mechem (2013), A PDF-based microphysics parameterization for shallow cumulus clouds, J. Atmos. Sci., 71(3), 1070-1089, doi:10.1175/JAS-D-13-0193.1. 
Koren, I., Y. J. Kaufman, D. Rosenfeld, L. A. Remer, and Y. Rudich (2005), Aerosol invigoration and restructuring of Atlantic convective clouds, Geophys. Res. Lett., 32, L14828, doi:10.1029/2005GL023187.

Koren, I., O. Altaratz, G. Feingold, Z. Levin, and T. Reisin (2009), Cloud's center of gravity-a compact approach to analyze convective cloud development, Atmos. Chem. Phys., 9(1), 155-161, doi:10.5194/acp-9-155-2009.

Koren, I., G. Dagan, and O. Altaratz (2014), From aerosol-limited to invigoration of warm convective clouds, Science, 344(6188), 1143-1146, doi:10.1126/science.1252595.

Koren, I., O. Altaratz, and G. Dagan (2015), Aerosol effect on the mobility of cloud droplets, Environ. Res. Lett., 10(10), 104,011, doi:10.1088/ $1748-9326 / 10 / 10 / 104011$.

Lebo, Z. J., and J. H. Seinfeld (2011), Theoretical basis for convective invigoration due to increased aerosol concentration, Atmos. Chem. Phys., 11, 5407-5429, doi:10.5194/acp-11-5407-2011.

Milbrandt, J. A., and H. Morrison (2012), Prediction of graupel density in a bulk microphysics scheme, J. Atmos. Sci., 70(2), 410-429, doi:10.1175/JAS-D-12-0204.1.

Mordy, W. (1959), Computations of the growth by condensation of a population of cloud droplets, Tellus, 11(1), 16-44, doi:10.1111/ j.2153-3490.1959.tb00003.x.

Morrison, H., J. A. Curry, and V. I. Khvorostyanov (2005), A new double-moment microphysics parameterization for application in cloud and climate models. Part I: Description, J. Atmos. Sci., 62(6), 1665-1677, doi:10.1175/JAS3446.1.

Ovchinnikov, M., A. S. Ackerman, A. Avramov, A. Cheng, J. Fan, A. M. Fridlind, S. Ghan, J. Harrington, C. Hoose, and A. Korolev (2014), Intercomparison of large-eddy simulations of Arctic mixed-phase clouds: Importance of ice size distribution assumptions, J. Adv. Model Earth Sy., 6(1), 223-248, doi:10.1002/2013MS000282.

Pinsky, M., I. P. Mazin, A. Korolev, and A. P. Khain (2012), Supersaturation and diffusional droplet growth in liquid clouds, J. Atmos. Sci., 70(9), 2778-2793, doi:10.1175/JAS-D-12-077.1.

Reutter, P., H. Su, J. Trentmann, M. Simmel, D. Rose, S. S. Gunthe, H. Wernli, M. O. Andreae, and U. Pöschl (2009), Aerosol-and updraft-limited regimes of cloud droplet formation: Influence of particle number, size and hygroscopicity on the activation of cloud condensation nuclei (CCN), Atmos. Chem. Phys., 9(18), 7067-7080, doi:10.5194/acp-9-7067-2009.

Rosenfeld, D., U. Lohmann, G. B. Raga, C. D. O'Dowd, M. Kulmala, S. Fuzzi, A. Reissell, and M. O. Andreae (2008), Flood or drought: How do aerosols affect precipitation?, Science, 321(5894), 1309-1313, doi:10.1126/science.1160606.

Rosenfeld, D., et al. (2014), Global observations of aerosol-cloud-precipitation-climate interactions, Rev. Geophys., 52, 750-808, doi:10.1002/ 2013RG000441.

Seifert, A., and K. D. Beheng (2001), A double-moment parameterization for simulating autoconversion, accretion and self-collection, Atmos. Res., 59-60(0), 265-281, doi:10.1016/S0169-8095(01)00126-0.

Seifert, A., and T. Heus (2013), Large-eddy simulation of organized precipitating trade wind cumulus clouds, Atmos. Chem. Phys., 13(11), 5631-5645, doi:10.5194/acp-13-5631-2013.

Seifert, A., T. Heus, R. Pincus, and B. Stevens (2015), Large-eddy simulation of the transient and near-equilibrium behavior of precipitating shallow convection, J. Adv. Model Earth Sy., 7(4), 1918-1937, doi:10.1002/2015MS000489.

Seigel, R. B. (2014), Shallow cumulus mixing and subcloud-layer responses to variations in aerosol loading, J. Atmos. Sci., 71(7), 2581-2603, doi:10.1175/JAS-D-13-0352.1.

Seiki, T., and T. Nakajima (2013), Aerosol effects of the condensation process on a convective cloud simulation, J. Atmos. Sci., 71(2), 833-853, doi:10.1175/JAS-D-12-0195.1.

Siebesma, A. P., C. S. Bretherton, A. Brown, A. Chlond, J. Cuxart, P. G. Duynkerke, H. Jiang, M. F. Khairoutdinov, D. Lewellen, and C. H. Moeng (2003), A large eddy simulation intercomparison study of shallow cumulus convection, J. Atmos. Sci., 60(10), 1201-1219, doi:10.1175/ 1520-0469(2003)60<1201:ALESIS > 2.0.CO;2.

Squires, P. (1958), The microstructure and colloidal stability of warm clouds, Tellus, 10(2), 256-261, doi:10.1111/j.2153-3490.1958.tb02011.x. Stevens, B. (2007), On the growth of layers of nonprecipitating cumulus convection, J. Atmos. Sci., 64(8), 2916-2931, doi:10.1175/JAS3983.1. Stevens, B., and G. Feingold (2009), Untangling aerosol effects on clouds and precipitation in a buffered system, Nature, 461(7264), 607-613, doi:10.1038/nature08281.

Stevens, B., and A. Seifert (2008), Understanding macrophysical outcomes of microphysical choices in simulations of shallow cumulus convection, J. Meteorol. Soc. Japan. Ser. II, 86A, 143-162, doi:10.2151/jmsj.86A.143.

Tao, W.-K., J. Simpson, and M. McCumber (1989), An ice-water saturation adjustment, Mon. Weather Rev., 117(1), 231-235, doi:10.1175/ 1520-0493(1989)117<0231:AIWSA >2.0.CO;2.

Tao, W.-K., J.-P. Chen, Z. Li, C. Wang, and C. Zhang (2012), Impact of aerosols on convective clouds and precipitation, Rev. Geophys., 50, RG2001, doi:10.1029/2011RG000369.

Twomey, S. (1977), The influence of pollution on the shortwave albedo of clouds, J. Atmos. Sci., 34(7), 1149-1152, doi:10.1175/ 1520-0469(1977)034<1149:TIOPOT>2.0.CO;2.

Wang, C. (2005), A modeling study of the response of tropical deep convection to the increase of cloud condensation nuclei concentration: 1. Dynamics and microphysics, J. Geophys. Res., 110, D21211, doi:10.1029/2004JD005720.

Warner, C., J. Simpson, D. W. Martin, D. Suchman, F. R. Mosher, and R. F. Reinking (1979), Shallow convection on day 261 of GATE/ mesoscale arcs, Mon. Weather Rev., 107(12), 1617-1635, doi:10.1175/1520-0493(1979)107<1617:SCODOG>2.0.CO;2.

Warner, J. (1968), A reduction in rainfall associated with smoke from sugar-cane fires-An inadvertent weather modification?, J. Appl. Meteorol., 7(2), 247-251, doi:10.1175/1520-0450(1968)007<0247:ARIRAW>2.0.CO;2.

Xue, H. W., and G. Feingold (2006), Large-eddy simulations of trade wind cumuli: Investigation of aerosol indirect effects, J. Atmos. Sci., 63(6), 1605-1622, doi:10.1175/jas3706.1.

Xue, H. W., G. Feingold, and B. Stevens (2008), Aerosol effects on clouds, precipitation, and the organization of shallow cumulus convection, J. Atmos. Sci., 65(2), 392-406, doi:10.1175/2007jas2428.1.

Yuan, T., L. A. Remer, and H. Yu (2011), Microphysical, macrophysical and radiative signatures of volcanic aerosols in trade wind cumulus observed by the A-Train, Atmos. Chem. Phys., 11(14), 7119-7132, doi:10.5194/acp-11-7119-2011.

Zuidema, P., Z. Li, R. J. Hill, L. Bariteau, B. Rilling, C. Fairall, W. A. Brewer, B. Albrecht, and J. Hare (2012), On trade wind cumulus cold pools, J. Atmos. Sci., 69(1), 258-280, doi:10.1175/JAS-D-11-0143.1. 